\title{
Immunological Properties of Neural Crest Cells Derived from Human Induced Pluripotent Stem Cells
}

\author{
Shota Fujii, ${ }^{1,2}$ Satoru Yoshida, ${ }^{3}$ Emi Inagaki, ${ }^{1,4,5}$ Shin Hatou, ${ }^{1}$ Kazuo Tsubota, \\ Masayo Takahashi, ${ }^{2}$ Shigeto Shimmura, ${ }^{1}$ and Sunao Sugita ${ }^{2}$
}

Collecting sufficient quantities of primary neural crest cells (NCCs) for experiments is difficult, as NCCs are embryonic transient tissue that basically does not proliferate. We successfully induced NCCs from human induced pluripotent stem cells (iPSCs) in accordance with a previously described method with some modifications. The protocol used in this study efficiently produced large amounts of iPSC-derived NCCs (iPSC-NCCs). Many researchers have recently produced large amounts of iPSC-NCCs and used these to examine the physiological properties, such as migratory activity, and the potential for medical uses such as wound healing. Immunological properties of NCCs are yet to be reported. Therefore, the purpose of this study was to assess the immunological properties of human iPSCNCCs. Our current study showed that iPSC-NCCs were hypoimmunogenic and had immunosuppressive properties in vitro. Expression of HLA class I molecules on iPSC-NCCs was lower than that observed for iPSCs, and there was no expression of HLA class II and costimulatory molecules on the cells. With regard to the immunosuppressive properties, iPSC-NCCs greatly inhibited T cell activation (cell proliferation and production of inflammatory cytokines) after stimulation. iPSC-NCCs constitutively expressed membrane-bound TGF- $\beta$, and TGF- $\beta$ produced by iPSCNCCs played a critical role in T cell suppression. Thus, cultured human NCCs can fully suppress T cell activation in vitro. This study may contribute to the realization of using stem cell-derived NCCs in cell-based medicine.

Keywords: eye, neural crest cells, immunosuppression, T cells

\section{Introduction}

$\mathrm{N}$ EURAL CREST CELLS (NCCs) are vertebrate-specific, transient, multipotent migratory stem cells that give rise to a wide range of cell and tissue types throughout the body [1]. It has been reported that corneal endothelium [2], gingivae [3,4], oral mucosal progenitor cells [5], and part of the mesenchymal stem cells (MSCs) [6] are derived from NCCs and exhibit immunosuppressive properties in vitro. However, corneal endothelial cells also express PD-L1 (B7-H1) and TGF- $\beta$, which inhibit T cell proliferation and induce regulatory $T$ cells $[7,8]$. Gingivae express the Fas ligand, which then induces $T$ cell apoptosis [3]. Oral mucosal progenitor cells can inhibit lymphocyte proliferation in mixed lymphocyte cultures [5]. Numerous studies have illustrated the ability of human MSCs to inhibit T cell proliferation in vitro and promote the expansion of regulatory T cells [9-13]. Moreover, MSC infusion has been shown to be an effective treatment of steroid-refractory acute graft-versus-host disease after bone marrow transplantation $[14,15]$ and is now being used in clinics. Human induced pluripotent stem cell (iPSC)-derived MSCs also have immunosuppressive properties and can prolong pancreatic islet survival after islet transplantation in streptozocin-induced diabetic mice [16]. Thus, NCC-derived differentiated cells/tissues exhibit immunosuppressive properties.

Previous reports have described NCC induction protocols from human iPSCs [17-20]. NCCs derived from iPSCs (iPSCNCCs) were reported to have a potential use in wound healing of diabetic neuropathy [21] and tendon repair [22] in vivo. However, there are yet to be any studies that have investigated the interaction of NCCs with specific immune cell subtypes. It was reported that iPSC-NCCs were effective in treating congenital aganglionic megacolon (Hirschsprung's disease) [23,24]. Human iPSC-NCCs have been shown to migrate and differentiate into functional neurons in aganglionic human gut tissue in vitro [23]. Human iPSC-NCCs restore mature ganglia and neurons in human intestinal organoid-derived tissue-engineered small

\footnotetext{
${ }^{1}$ Department of Ophthalmology, Keio University School of Medicine, Tokyo, Japan.

${ }^{2}$ Laboratory for Retinal Regeneration, RIKEN Center for Biosystems Dynamics Research, Kobe, Japan.

${ }^{3}$ Department of Regenerative Medicine, Fujita Health University School of Medicine, Aichi, Japan.

${ }_{5}^{4}$ Department of Physiology, Keio University School of Medicine, Tokyo, Japan.

${ }^{5}$ Japan Society for the Promotion of Science, Tokyo, Japan.
}

(C) Shota Fujii et al. 2018; Published by Mary Ann Liebert, Inc. This Open Access article is distributed under the terms of the Creative Commons Attribution Noncommercial License (http://creativecommons.org/licenses/by-nc/4.0/) which permits any noncommercial use, distribution, and reproduction in any medium, provided the original author(s) and the source are cited. 
intestine [24]. Li et al. suggested that iPSC-NCCs may be an attractive tool that can be used for studying the pathogenesis of gastrointestinal disorders, as they represent a potentially ideal cell source for enteric neural transplantation treatments [23]. The multipotency of the NCCs suggests a promising role for iPSC-NCCs as a source for cell-based therapy. When the iPSC-NCCs are clinically applied, it is important to investigate their immunological properties.

Therefore, the purpose of this study was to assess the immunological properties of iPSC-NCCs in vitro. After successfully inducing NCCs from human iPSCs in accordance with a previous method with some modifications [25,26], we used the iPSC-NCCs as effectors and immune cells as targets in vitro to evaluate the immunosuppression by NCCs.

\section{Materials and Methods \\ Culture of iPSCs and the induction of NCCs}

Human iPSC lines 253G1 and 201B7, which are generated from adult skin fibroblasts [27,28], were obtained from the Riken BioResource Center (Ibaraki, Japan). The iPSCs were cultured under feeder-free and serum-free conditions with AK03N medium (Ajinomoto, Tokyo, Japan) in six-well culture plates coated with iMatrix-511 (Nippi, Tokyo, Japan) as previously described [29]. The iPSCs were subcultured once a week, with the medium changed daily. The iPSCs were differentiated into NCCs according to a previously described method [25,26] with some modifications. Briefly, after the undifferentiated iPSCs reached confluence in culture, the iPSCs were dissociated with Accutase (Millipore, Temecula, CA) and seeded first on a 3-D culture plate (EZSPHERE ${ }^{\circledR}$; AGC Techno Glass, Shizuoka, Japan) [30] at a density of $2 \times 10^{5}$ cells $/ \mathrm{mL}$ in an embryoid body (EB) induction medium, which was composed of DMEM/F12 (Sigma-Aldrich, St. Louis, MO) supplemented with 1\% N-2 (Gibco, Grand Island, NY), 2\% MACS $^{\circledR}$ NeuroBrew-21 (Miltenyi Biotec, Auburn, CA), $2 \mathrm{mM} \mathrm{L-glutamine} \mathrm{(Sigma-Aldrich),} 20 \mathrm{ng} / \mathrm{mL}$ recombinant human epidermal growth factor (EGF: PeproTech, Rocky Hill, NJ), $1 \%$ penicillin/streptomycin (Gibco), and $10 \mu \mathrm{M}$ Y-27632 (Wako, Osaka, Japan). The spent medium was changed once on EB culture day 4, with uniformly sized EBs forming in 7 days. Subsequently, the EBs were replated on a noncoated $10 \mathrm{~cm}$ dish in NCC induction medium, DMEM/F12 with $1 \% \mathrm{~N}-2,2 \mathrm{mM}$ L-glutamine, $1 \%$ penicillin/streptomycin, $20 \mathrm{ng} / \mathrm{mL}$ EGF, $20 \mathrm{ng} / \mathrm{mL}$ recombinant human fibroblast growth factor-basic (bFGF: Wako), and $5 \mu \mathrm{g} / \mathrm{mL}$ heparin (SigmaAldrich). The culture dish was left untouched for the first 3 days to allow the EBs to attach to the culture dish and the induced NCCs to migrate from the attached EBs, after which the spent medium was changed on days $4,8,11,13$, and 14 in conjunction with the replating of the EBs. NCC induction was completed by day 14. The iPSC-NCCs were used for subsequent experiments.

This study was performed in accordance with ethics protocols approved by the Keio University Ethics Committee and the Institutional Review Board at RIKEN Center for Developmental Biology. Informed consent was obtained from all healthy volunteers.

\section{Flow cytometric analysis}

After washing, iPSC-NCCs and iPSCs were harvested and resuspended at a density of $5 \times 10^{5}$ cells $/ \mathrm{mL}$. Specimens were then incubated in PE, FITC, or PE/Cy5 conjugated primary antibody or PI solution (Dojindo, Kumamoto, Japan; catalog \#341-07881) at $4^{\circ} \mathrm{C}$ for $30 \mathrm{~min}$ and washed thrice. Flow cytometric analysis was performed using the Canto ${ }^{\mathrm{TM}}$ II flow cytometer (BD Biosciences, San Jose, CA), with the data analyzed using the FlowJo software (Tree Star, Ashland, OR). The primary antibodies included PE-conjugated anti-human SSEA-4 (eBioscience, San Diego, CA; catalog \#12-8843), PEconjugated anti-human CD271 (BioLegend, San Diego, CA; catalog \#345106), PE/Cy5-conjugated anti-human CD49d (BioLegend; catalog \#304306), FITC-conjugated anti-human HLA class I (Sigma-Aldrich; catalog \#F5662), PE-conjugated anti-human 32 -microglobulin (BioLegend; catalog \#316306), FITC-conjugated anti-human HLA-DR, DP, DQ (BD Biosciences; catalog \#555558), FITC-conjugated anti-human CD80 (B7-1: eBioscience; catalog \#11-0809), PE-conjugated anti-human CD86 (B7-2: eBioscience; catalog \#12-0862), PEconjugated anti-human CD274 (PD-L1: eBioscience; catalog \#12-5983), PE-conjugated anti-human CD273 (PD-L2: BD Pharmingen, San Jose, CA; catalog \#558066), and the appropriate isotype-matched controls. Expression of TGF- $\beta 2$ in iPSC-NCCs and iPSCs (control) was assessed by flow cytometry. Cell-surface staining (no intracellular staining) was performed for the expression of TGF- $\beta 2$ using these cells. After human Fc block staining, these cells were stained with anti-human TGF- $\beta 2$ abs (Abcam, Cambridge, United Kingdom; catalog \#ab66045) at $4^{\circ} \mathrm{C}$ for $30 \mathrm{~min}$. iPSC-NCCs were then stained with Alexa Fluor-488-labeled anti-rabbit IgG (2nd abs: Life Technologies, Carlsbad, CA; catalog \#A11008) at $4^{\circ} \mathrm{C}$ for $30 \mathrm{~min}$, and the cells were evaluated by fluorescenceactivated cell sorting (FACS) analysis.

\section{Immunohistochemistry}

Cells were fixed with methanol for $15 \mathrm{~min}$ at $-30^{\circ} \mathrm{C}$, permeabilized with $0.2 \%$ Triton X-100-PBS (Sigma-Aldrich) at room temperature for $15 \mathrm{~min}$, and blocked in a solution of PBS containing $1 \%$ bovine serum albumin (Sigma-Aldrich), followed by an overnight incubation in primary antibody solutions at $4^{\circ} \mathrm{C}$. After three washes in $0.05 \%$ Tween-20-PBS (Sigma-Aldrich), cells were incubated with Alexa fluorescently conjugated secondary antibodies and $5 \mu \mathrm{g} / \mathrm{mL} 4^{\prime}$, 6-diamidino-2-phenylindole dihydrochloride (DAPI: Invitrogen, Carlsbad, CA) at room temperature for another $60 \mathrm{~min}$. After three washes in PBS, labeled cells were imaged with a fluorescence microscope (Olympus, Tokyo, Japan).

Primary antibodies and their working dilutions were as follows: mouse anti-human nerve growth factor receptor (NGFR: Advanced Targeting Systems, San Diego, CA; catalog \#AB-N07, 1:200 dilution) and mouse anti-human transcription factor AP-2 alpha (TFAP2A: Developmental Studies Hybridoma Bank, Iowa City, IA; catalog \#3B5, 1:200 dilution). The secondary antibodies used were the corresponding Alexa488 fluorescent-labeled antibodies (Life Technologies, catalog \#A11029, 1:1000 dilution). Expressions of membrane bound TGF- $\beta 2$ on iPSC-NCCs and iPSCs (control) were also assessed by immunohistochemistry using the same antibodies as those in the FACS analysis.

\section{Quantitative real-time polymerase chain reaction}

Total RNA from iPSC-NCCs and control iPSCs was purified using the High Pure RNA Isolation Kit (Roche, Basel, 
Table 1. Primer Sequences and Probe Numbers Used in Quantitative Real-Time Polymerase Chain Reaction

\begin{tabular}{|c|c|c|c|}
\hline Genes & Forward sequence $\left(5^{\prime}-3^{\prime}\right)$ & Reverse sequence (5'-3') & Probe \\
\hline$A C T B$ & ccagaggcgtacagggatag & ccaaccgcgagaagatga & \#64 \\
\hline$N G F R$ & tcatccetgtctattgetcca & tgttctgcttgcagctgttc & \#66 \\
\hline SNAI2 & tggttgcttcaaggacacat & gcaaatgctctgttgcagtg & $\# 7$ \\
\hline SOX10 & ggctccccatgtcagat & ctgtcttcggggtggttg & $\# 21$ \\
\hline TFAP $2 A$ & acatgctcetggctacaaaac & aggggagatcggtcctga & \#62 \\
\hline $\operatorname{Lin} 28 A$ & gaagcgcagatcaaaaggag & gctgatgctctggcagaagt & $\# 23$ \\
\hline Nanog & atgcctcacacggagactgt & cagggetgtcctgaataagc & \#69 \\
\hline$T G F-\beta 1$ & cagccggttgctgaggta & gcagcacgtggagctgta & $\# 72$ \\
\hline$T G F-\beta 2$ & cagatgettctggatttatggtatt & ccaaagggtacaatgccaac & \#67 \\
\hline
\end{tabular}

$A C T B$; actin beta, NGFR; nerve growth factor receptor, SNAI2; snail family transcriptional repressor 2, SOX10; sex determining region Ybox 10, TFAP $2 A$; transcription factor AP-2 alpha, $T G F-\beta 1$; transforming growth factor beta 1 , and $T G F-\beta 2$; transforming growth factor beta 2.

Switzerland). One $\mu \mathrm{g}$ of total RNA was reverse transcribed for single-standard cDNA using the Transcriptor First Strand cDNA Synthesis Kit (Roche) in accordance with the manufacturer's instructions. Quantitative real-time polymerase chain reaction (qRT-PCR) with the LightCycler 480 Probe Master (Roche) was performed using the LightCycler ${ }^{\circledR} 480$ Instrument II (Roche). Table 1 lists the primer sequences. The qRT-PCR was performed by denaturation at $95^{\circ} \mathrm{C}$ for $10 \mathrm{~min}$, followed by 45 cycles of denaturation at $95^{\circ} \mathrm{C}$ for $10 \mathrm{~s}$, annealing at $60^{\circ} \mathrm{C}$ for $30 \mathrm{~s}$, and extension at $72^{\circ} \mathrm{C}$ for $1 \mathrm{~s}$. All amplifications were performed in triplicate, with $\beta$-actin used for normalization of the RNA content. A negative control with no cDNA was also used for each analysis.

\section{Adipogenic, chondrogenic, and osteogenic differentiation}

To validate whether iPSC-NCCs maintain multipotency, iPSC-NCCs were plated at a density of $5 \times 10^{5}$ cells in $35 \mathrm{~mm}$ dishes. Cells were fed every 2 days by completely replacing the medium with NCC induction medium (3-5 days). At $100 \%$ confluence, we performed adipogenic differentiation by treating the iPSC-NCCs with hMSC Adipogenic BulletKit (Lonza, Basel, Switzerland; catalog \#PT-3004) for 3 weeks according to the manufacturer's protocol, followed by staining with oil red $\mathrm{O}$ (Muto Pure Chemicals, Tokyo, Japan; catalog \#40491) to detect lipids. A pellet culture system was used to evaluate the capacity of iPSC-NCCs to differentiate into chondrocytes. iPSC-NCCs were applied to a pellet at a density of $5 \times 10^{5}$ cells and cultured in hMSC Chondro BulletKit (Lonza; catalog \#PT-3003). The medium was changed every 3-4 days. After 4 weeks in culture, the induced cartilage tissue was fixed with $4 \%$ formaldehyde, sliced, and stained with 1\% Alcian Blue (Amresco, Solon, OH; catalog \#0298). To investigate the osteogenic differentiation capacity of iPSC-NCCs, confluent iPSC-NCCs in $35 \mathrm{~mm}$ dishes were treated with hMSC Osteogenic BulletKit (Lonza; catalog \#PT-3002). The medium was changed every 2-3 days. After 2-3 weeks, the cells were stained with Alizarin Red S (Nacalai Tesque, Kyoto, Japan; catalog \#01303-52), rinsed with water, and examined by microscopy.

\section{$T$ cell-NCC assay of cell proliferation}

Human peripheral blood mononuclear cells (PBMCs) were obtained from the blood of five healthy donors by Lympho- prep (Stemcell Technologies, Vancouver, BC) density gradient centrifugation in accordance with the manufacturer's instructions. PBMCs were incubated in RPMI 1640 (Nacalai Tesque) containing 10\% FBS supplemented with human recombinant interleukin-2 (rIL-2; BD Biosciences). To assess immunosuppressive effects of iPSC-NCCs in vitro, we used a mixed lymphocyte reaction (MLR) test, with iPSCs used as a negative control and iPSC-derived retinal pigment epithelial (iPSC-RPE) cells used as a positive control. iPSC-RPE cells were established in accordance with a previously reported method [31,32]. PBMCs were categorized into four groups as follows: PBMC monoculture (PBMC only: $3 \times 10^{6}$ cells/ well), PBMC coculture with iPSC-NCCs $\left(1 \times 10^{6}\right.$ cells/well $)$, PBMC coculture with iPSCs, and PBMC coculture with iPSC-RPE cells. After $120 \mathrm{~h}$ of incubation, PBMCs were collected and analyzed by flow cytometry of the PBMC fraction. In the $\mathrm{T}$ cell suppression assay with iPSC-NCCs, anti-human CD3 antibody $(1 \mu \mathrm{g} / \mathrm{mL}$, Ancell, Bayport, MN; catalog \#144-020) and anti-human CD28 antibody $(1 \mu \mathrm{g} / \mathrm{mL}$, BD Pharmingen; catalog \#555725) were used for the $\mathrm{T}$ cell stimulation. After $72 \mathrm{~h}$ of incubation, PBMCs were collected and analyzed by flow cytometry.

For the TGF- $\beta$ block assay, we used TGF- $\beta$ RI Kinase Inhibitor VI (SB431542; Sigma-Aldrich; catalog \#S4317). After adding 1,5 , and $10 \mu \mathrm{M}$ of SB431542 to the PBMC coculture with iPSC-NCCs, PBMCs were then incubated in RPMI1640 medium plus rIL-2 and stimulated with antiCD3/CD28 antibodies. PBMCs were categorized into three groups as follows: PBMC monoculture, PBMC coculture with iPSC-NCCs, and PBMC coculture with iPSC-NCCs plus SB431542.

For the Ki-67 FACS analysis, PBMCs were fixed and permeabilized with $70 \%$ ethanol at $-30^{\circ} \mathrm{C}$ for $1 \mathrm{~h}$, followed by washing thrice using cell staining buffer (BioLegend). Subsequently, the cells were intracellularly stained with PEconjugated anti-Ki-67 antibody (BioLegend; catalog \#350504), APC-conjugated anti-CD3 (BioLegend; catalog \#300412), APC-conjugated anti-CD4 (eBioscience; catalog \#17-0049), anti-CD8 (eBioscience; catalog \#17-0088), anti-CD11b (Miltenyi Biotec; catalog \#130-098-088), or anti-CD56 antibodies (BioLegend; catalog \#304604).

\section{Transwell culture assays}

Transwell chambers with a $0.3 \mu \mathrm{m}$ pore size membrane (Corning Costar, Cambridge, MA) were used to separate the 
lymphocytes physically from the iPSC-NCCs. In the transwell assay, PBMCs $\left(1.0 \times 10^{6}\right.$ cells/well $)$ were added to the upper wells of a transwell plate. PBMCs were cultured in the presence or absence of iPSC-NCCs $\left(1.0 \times 10^{5}\right.$ cells/ well). Cultures were plated in triplicate and incubated for 3 days. After incubation, PBMCs were collected and stained with PE-conjugated anti-Ki-67 antibody and APCconjugated anti-CD3 antibody. $\mathrm{T}$ cell proliferation (Ki-67 FACS) was assessed by flow cytometry.

\section{Cytokine measurements}

Concentrations of IFN- $\gamma$ in the supernatant of the PBMC monoculture, PBMCs cocultured with iPSCs, and iPSCNCCs were examined using ELISA in accordance with the manufacturer's manual (R\&D Systems, Minneapolis, MN). Each result was evaluated statistically, with $P<0.05$ defined as being significant. In addition, concentrations of IFN $-\gamma$ in the supernatant of the PBMC monoculture, PBMC coculture with iPSC-NCCs, and PBMC coculture with iPSC-NCCs plus SB431542 were also examined.

For the FACS analysis, double staining of CD4 and IFN- $\gamma$ was performed to determine the proportion of the $\mathrm{CD} 4^{+}$IFN$\gamma$ expressing $\mathrm{T}$ cells. Intracellular staining was performed to determine the expression of IFN- $\gamma$. Before staining for IFN- $\gamma$, PBMCs were prestimulated with $\mathrm{T}$ cell stimulation materials (CytoStim; Miltenyi Biotec) for $1 \mathrm{~h}$, and then cells were incubated for an additional $4 \mathrm{~h}$ in the presence of a protein transport inhibitor (BD GolgiStop ${ }^{\mathrm{TM}}$; BD Biosciences). Cells were then treated with an intracellular staining material (BD Cytofix/Cytoperm Kits, BD Pharmingen). After human Fc block staining, these T cells were stained with APC-labeled anti-human CD4 abs (Miltenyi Biotec) and PE-labeled antihuman IFN $-\gamma\left(\right.$ R\&D Systems) at $4^{\circ} \mathrm{C}$ for $30 \mathrm{~min}$. PBMCs were also stained with PE-labeled isotype control abs (mouse $\mathrm{IgG})$ at $4^{\circ} \mathrm{C}$ for $30 \mathrm{~min}$.

\section{DNA microarray}

For comparing the gene expression between iPSCs and iPSC-NCCs, after the cells were harvested, the total RNA of iPSCs $(n=2)$ and iPSC-NCCs $(n=2)$ was extracted using a High Pure RNA Isolation Kit (Roche). Whole Human Genome Oligo Microarray (4*44K, Agilent Technologies, Santa Clara, CA) analysis was then performed by Filgen (Aichi, Japan). Briefly, RNA quantity and quality were measured by NanoDrop ND-1000 (NanoDrop Technologies, Inc., Wilmington, DE). RNA integrity was assessed by standard denaturing agarose gel electrophoresis. Sample labeling and array hybridization were performed according to the Agilent One-Color Microarray-Based Gene Expression Analysis protocol. We registered these data in the GEO database (Accession No. GSE109136).

Next, the gene expressions between inflamed and normal conditions of iPSC-NCCs were compared. For the inflamed condition, iPSC-NCCs $\left(1.0 \times 10^{6}\right.$ cells/well $)$ were incubated in the presence of PBMC mix (MLR; $3.0 \times 10^{6}$ cells/well) in a transwell culture plate. To avoid contamination with iPSCNCCs, PBMCs were incubated in an upper well of the transwell plate. For the normal condition, iPSC-NCCs were incubated in the absence of PBMCs. For both conditions, iPSC-NCCs were incubated in RPMI1640 medium. After incubation for $120 \mathrm{~h}$, the total RNA of iPSC-NCCs (inflamed condition, $n=2$ ) and iPSC-NCCs (normal condition, $n=2$ ) was extracted. The procedures were performed as previously described. We also registered these data in the GEO database (Accession No. GSE116110).

\section{Statistical analysis}

All experiments were repeated at least thrice, and data are expressed as the mean \pm standard deviation (SD). A twotailed $t$-test was used for all of the statistical analyses. Results were considered significant when $P<0.05$.

\section{Results \\ Differentiation and identification of iPSC-derived NCCs}

In the first step, we established human iPSC-derived NCCs. iPSC-NCCs were successfully induced from human iPSCs after 3 weeks of differentiation. During the differentiation, the cells gradually changed into a dendritic morphology (Fig. 1A). Flow cytometry staining revealed that the iPSCs were positive for stage-specific embryonic antigen-4 (SSEA4), which is a pluripotency marker, while the iPSC-NCCs were negative for SSEA4 (Fig. 1B). iPSCNCCs highly expressed CD271 (NGFR) and CD49 d (both NCC markers), compared with iPSCs (Fig. 1C). iPSCs expressed only CD271 and not CD49d. Immunofluorescence staining revealed that the iPSC-NCCs were positive for neural crest markers, NGFR and TFAP2A (Fig. 1D). In addition, qRT-PCR showed that iPSC-NCCs expressed low levels of the pluripotency markers, Nanog and Lin 28A. The expression of the neural crest markers, $N G F R$, snail family transcriptional repressor 2 (SNAI2), sex determining region Y-box 10 (SOX10), and TFAP2A, were higher in the iPSCNCCs versus the iPSCs (Fig. 1E).

In addition, we successfully induced adipocytes, chondrocytes, and osteocytes from iPSC-NCCs (Fig. 1F). We validated the NCC induction protocol in two different iPS cell lines $(201 \mathrm{~B} 7,253 \mathrm{G} 1)$, with the results being the same in both cell lines.

\section{Expression of HLA and costimulatory molecules on iPSC-NCCS}

To confirm the immunogenicity in iPSC-NCCs, we examined the expression of HLA and costimulatory molecules on the iPSC-NCCs. At first, we confirmed that analyzed cells (iPSCs and iPSC-NCCs) were $>99 \%$ negative for PI (which stains the dead cells). Our results showed that iPSCNCCs exhibited a lower expression of HLA class I, but had no expression of HLA class II (Fig. 2A). Similarly, the iPSC-NCCs had a lower expression of $\beta 2$-microglobulin, which forms HLA class I, compared to the iPSCs (Fig. 2A). Furthermore, there was a statistically significant difference between the iPSCs and iPSC-NCCs (Fig. 2B). In addition, we found no difference in the costimulatory molecule expression between the iPSCs and iPSC-NCCs (Fig. 2C). For example, iPSC-NCCs, as well as iPSCs, did not express CD80 (B7-1), CD86 (B7-2), CD274 (PD-L1), or CD273 (PD-L2) on their surface. In contrast, monocytes (positive control: from a healthy donor) clearly expressed these 

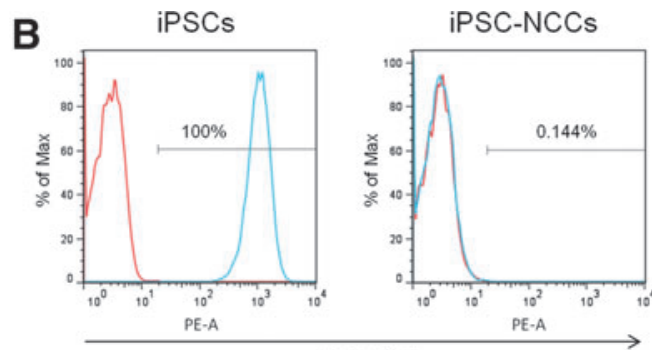

\section{SSEA4}
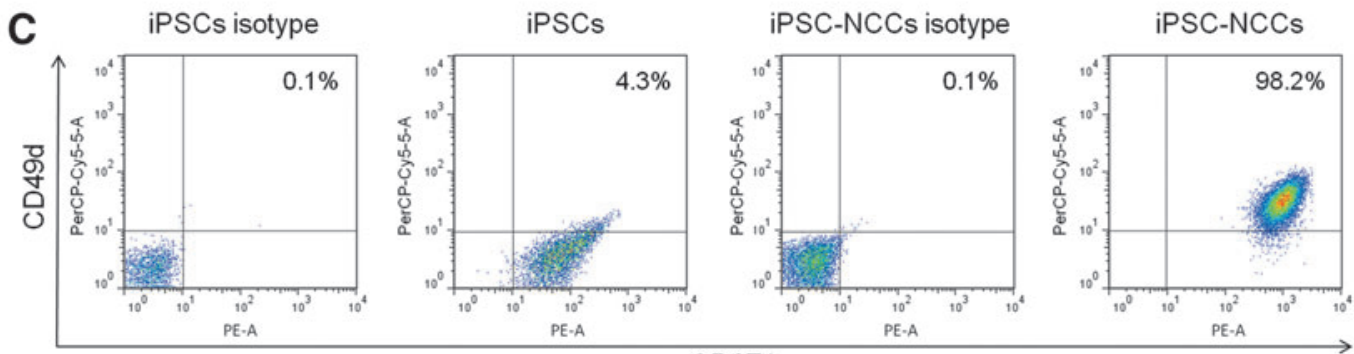

CD271

D

iPSC-NCCs
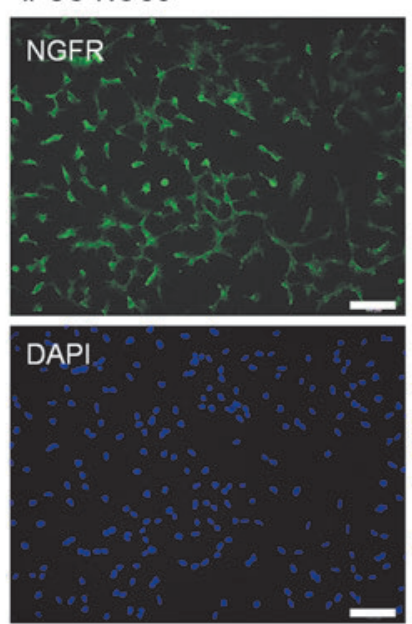

iPSC-NCCs

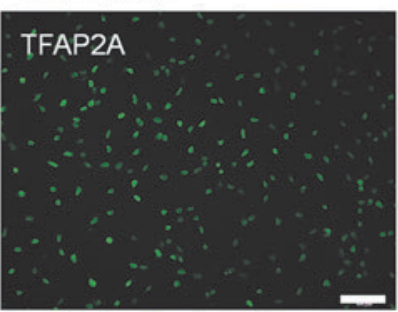

\section{DAPI}

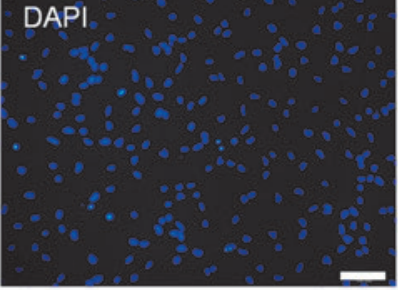

$E$

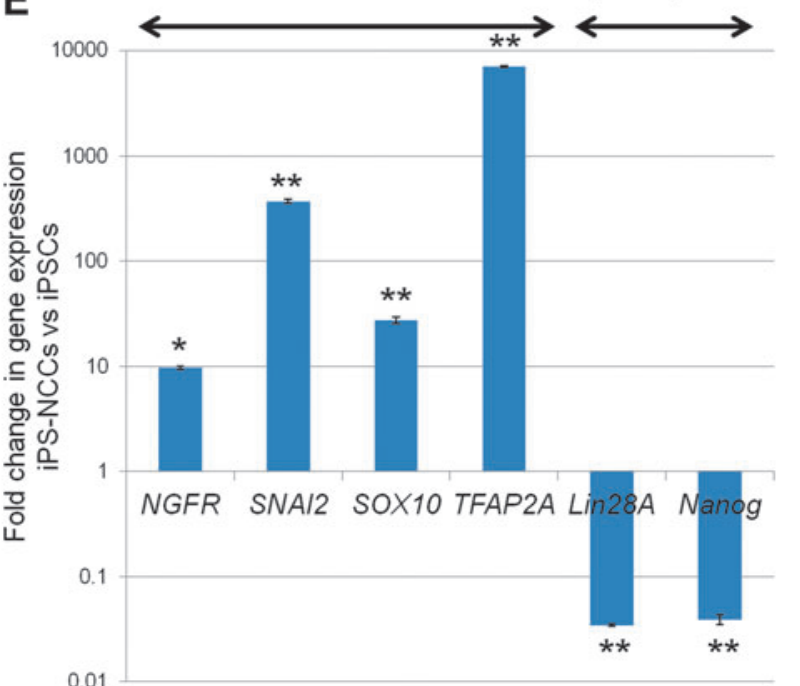

F

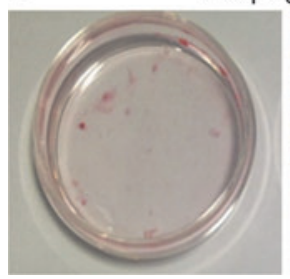

Adipogenesis

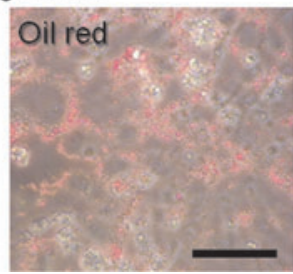

Chondrogenesis

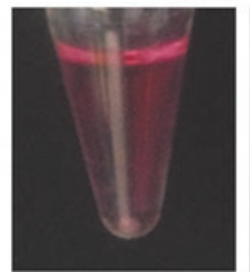

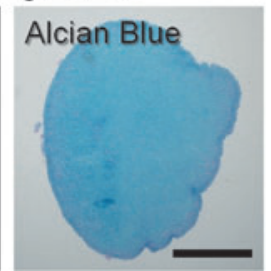

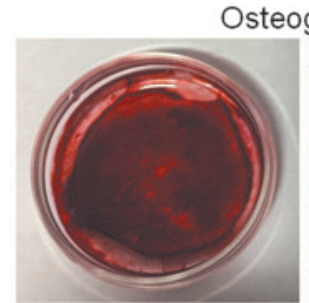

Osteogenesis

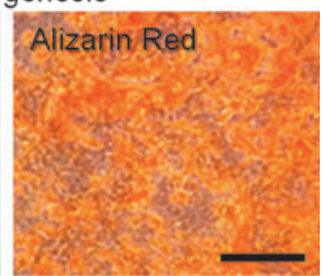

FIG. 1. Differentiation of NCCs from human iPS cells. (A) Bright-field image of iPSC-NCCs. Scale bars, $100 \mu \mathrm{m}$. (B) Expression of SSEA4 in iPSCs and iPSC-NCCs by flow cytometry analysis. iPSCs are positive, and iPSC-NCCs are negative for SSEA4. Red histogram; isotype control. (C) In the FACS analysis, iPSCs are negative for CD49 d and slightly positive for CD271 expression. iPSC-NCCs are clearly positive for CD49 d and CD271. Numbers in the FACS histograms indicate double positive cells. (D) Expression of NCC marker NGFR and TFAP2A. Immunocytochemistry analysis shows that iPSC-NCCs are positive for NGFR and TFAP2A. Cell nuclei were counterstained with DAPI. Scale bars, $100 \mu \mathrm{m}$. (E) Expression of NCC markers: qRTPCR data showing the expression of NGFR, SNAI2, SOX10, TFAP2A, Lin28A, and Nanog in iPSC-NCCs $(n=3)$ relative to iPSCs $(n=3)$. NGFR, SNAI2, SOX10, and TFAP2A are significantly upregulated in iPSC-NCCs, while Lin28A and Nanog are significantly downregulated in iPSC-NCCs when the detection of mRNA is compared in these cells. $* P<0.05$, $* * P<0.01$, when comparing the two groups. (F) Characterization and differentiation into adipocytes, chondrocytes, and osteocytes of iPSC-NCCs. iPSC-NCCs were differentiated into adipocytes. In adipocyte-differentiated cells, the accumulation of oil red O-stained lipid drops was observed. Scale bar, $200 \mu \mathrm{m}$. iPSC-NCCs were differentiated into chondrocytes. The pellet was verified by Alcian blue staining of cartilage proteoglycans. Scale bar, $500 \mu \mathrm{m}$. iPSC-NCCs were differentiated into osteocytes and exhibited enhanced calcium deposition by alizarin red S staining. Scale bar, $200 \mu \mathrm{m}$. iPSC, induced pluripotent stem cell; NCC, neural crest cell; qRT$\mathrm{PCR}$, quantitative real-time polymerase chain reaction. 

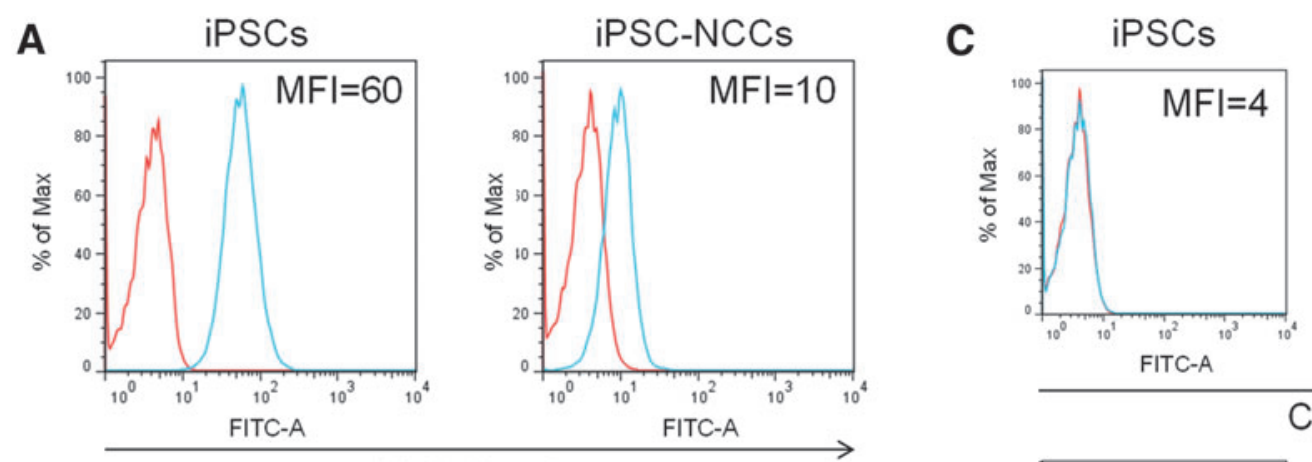

iPSC-NCCs

HLA class I
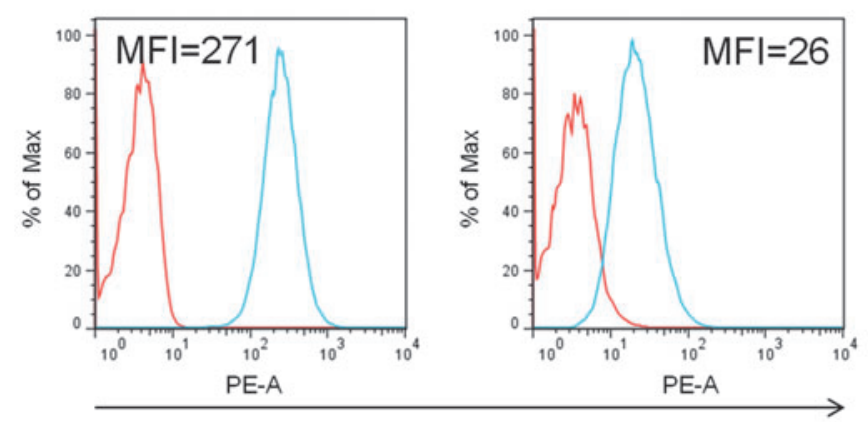

ß2-microglobulin
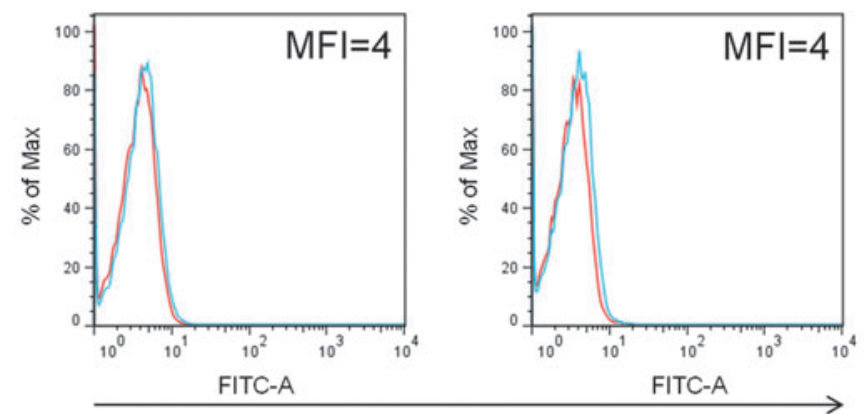

HLA class II
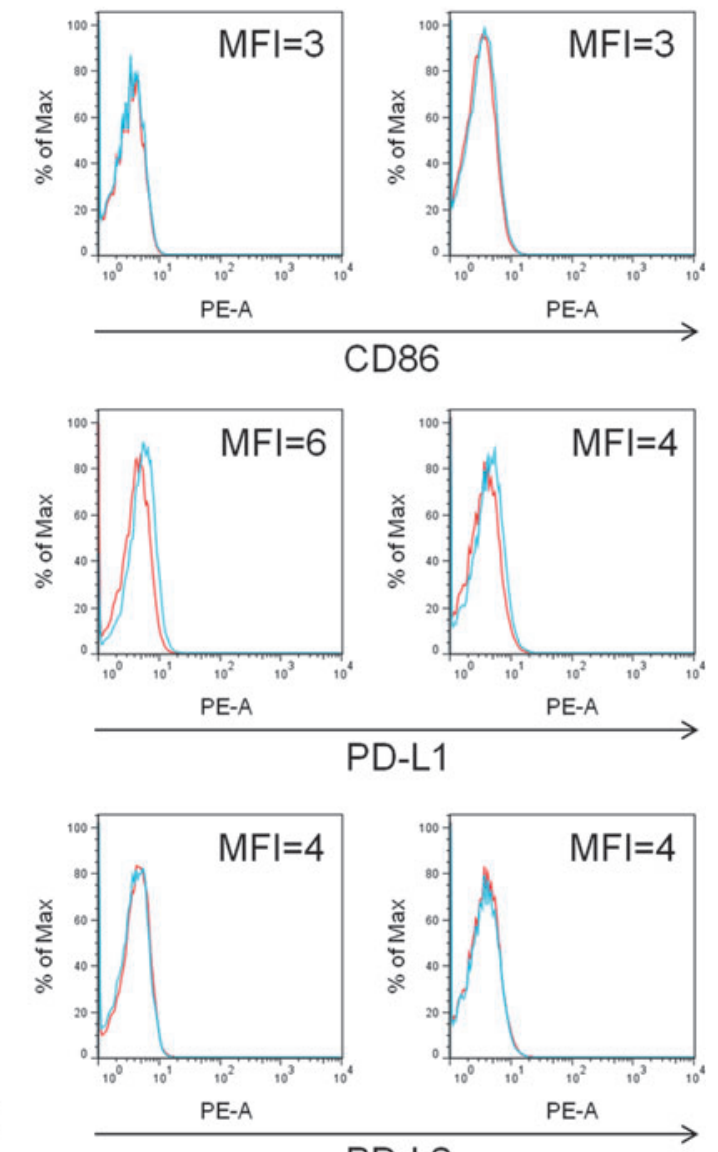

B HLA class I
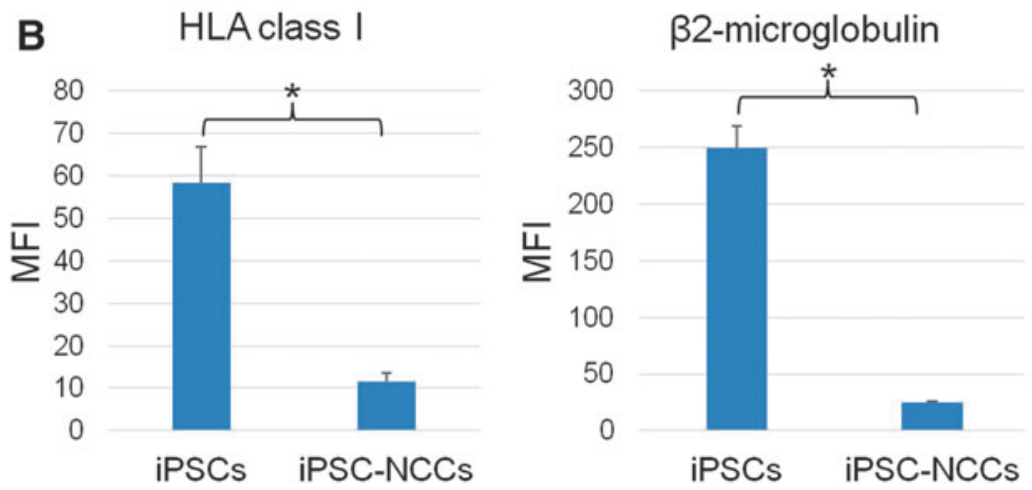

FIG. 2. Expression of HLA class I, class II, and costimulatory molecules on iPSC-NCCs. (A) For the flow cytometry analysis, HLA class I expression of iPSC-NCCs is lower compared with the iPSCs. Expression of $\beta 2$-microglobulin of the iPSC-NCCs is lower compared with iPSCs. Expression of HLA class II is not detected in either of the cells. MFI, mean fluorescence intensity. (B) MFI of HLA class I and $\beta 2$-microglobulin was also examined. Data are the mean \pm SD of three experiments. * $P<0.01$, comparing two groups. (C) Expressions of CD80 (B7-1), CD86 (B7-2), CD274 (PD-L1), and CD273 (PD-L2) failed to be detected in the iPSCs and iPSC-NCCs. Red histogram; isotype control. 
costimulatory molecules (data not shown). Thus, these results suggest that iPSC-NCCs have low immunogenicity.

\section{Suppression of the proliferation of inflammatory immune cells by iPSC-NCCs}

We examined whether established iPSC-NCCs have immunosuppressive effects in vitro. For this assay, we used the MLR test. In this experiment, iPSCs and iPSC-RPE cells were used as controls. Compared to a mix of PBMCs without NCCs, our results showed that iPSC-NCCs inhibited the proliferation of PBMCs (Fig. 3A). In contrast, iPSCs failed to suppress the proliferation of PBMCs, while iPSCRPE cells strongly inhibited the PBMC proliferation. Compared to using only the PBMC mix, the PBMC mix plus iPSC-NCCs significantly suppressed $\mathrm{CD} 4^{+}$helper $\mathrm{T}$ cells, $\mathrm{CD}^{+}$cytotoxic $\mathrm{T}$ cells, CD11 ${ }^{+}$monocytes/macrophages, and $\mathrm{CD}^{+} 6^{+}$natural killer (NK)/NKT cells (Fig. 3B). In addition, iPSC-NCCs did not increase the proliferation of PBMCs stimulated with anti-human CD3 and anti-CD28 antibodies in the absence of rIL-2 (Supplementary Fig. S1; Supplementary Data are available online at www.liebert pub.com/scd).

To induce $\mathrm{T}$ cell activation, our cultures also used $\mathrm{T}$ cell agonistic antibodies such as anti-human CD3 antibody and anti-human CD28 antibody. In these cocultures, our results showed that iPSC-NCCs strongly inhibited $\mathrm{CD}^{+}, \mathrm{CD}^{+}$, and $\mathrm{CD}^{+} \mathrm{T}$ cell proliferation in the PBMCs (Fig. 4A). There was a statistically significant difference between the PBMCs only without NCCs and the iPSC-NCCs, but not the iPSCs (Fig. 4B). Similarly, iPSC-NCCs also suppressed IFN- $\gamma$ expressing $\mathrm{CD}^{+} \mathrm{T}$ cells, as determined by FACS analysis, while iPSCs did not (Fig. 4C). There was a statistically significant difference between the PBMCs only without NCCs and the iPSC-NCCs, but not the iPSCs (Fig. 4D). In addition, PBMC-NCC cocultures contained significantly lower levels of IFN- $\gamma$ compared with controls (Fig. 4E). Thus, these data suggest that iPSC-NCCs are able to suppress the Th1-type $\mathrm{CD}^{+}$cells that secrete the inflammatory cytokine, IFN- $\gamma$. This result is consistent with the previous observation of the suppressive effect of iPSCNCCs on $\mathrm{CD}^{+}$and $\mathrm{CD}^{+} \mathrm{T}$ cells, CD $11 \mathrm{~b}^{+}$monocytes/ macrophages, and $\mathrm{CD}_{5} 6^{+} \mathrm{NK} / \mathrm{NKT}$ cells, which are potential producers of IFN- $\gamma$.

\section{Ability of iPSC-NCCs to suppress $T$ cell activation through cell contact}

To clarify the role that cell contact plays in the inhibition of T cell proliferation by NCCs, cells were separately cultured in culture plates. Transwell cell insert membranes, which contained PBMCs plus anti-human CD3 and anti- human CD28 antibodies, were placed in the wells. In the PBMC-NCC cocultures, $\mathrm{T}$ cell proliferation was significantly suppressed in the absence of the transwell membrane (Fig. 5A). However, iPSC-NCCs failed to suppress the $\mathrm{T}$ cell proliferation as contact was prohibited by the transwell membrane. There was a statistically significant difference between iPSC-NCCs and iPSC-NCCs plus cell insert (Fig. 5B). These results imply that cell contact molecules are essential for suppression of activated $\mathrm{T}$ cells by iPSCNCCs. Thus, NCCs can exclusively suppress T cell activation through immunosuppressive cell surface molecules.

\section{Survey for candidate immunosuppressive molecule(s) by iPSC-NCCs using microarray analysis}

Based on the immunosuppressive properties of the iPSCNCCs that appeared to be associated with the cell-to-cell contact molecules, we hypothesized that cell surface molecules on iPSC-NCCs were responsible for the suppression. To determine possible candidate molecules, we examined iPSC-NCCs using a microarray assay. For the assay, we prepared human iPSC-NCCs and control iPSCs. GeneChip analysis showed that there was downregulation of the mRNA expression of HLA class I and class II in iPSCNCCs compared with control iPSCs (Fig. 6A). These data indicated that iPSC-NCCs had poor immunogenicity after differentiation from iPSCs. Furthermore, these findings were confirmed by the flow cytometry results. Among the T cell related immunosuppressive factors, iPSC-NCCs highly expressed mRNA for $T G F-\beta 1$ and especially $T G F-\beta 2$, compared to iPSCs (Fig. 6B). Other factors such as FASL, PTGES, PTGES2, CD274, PDCD1LG2, IL10, NOS1, NOS2, NOS3, CD80, CD86, IDO1, IDO2, and TGF- $\beta 3$ were not involved in the expression of iPSC-NCCs. We also examined how gene expression of iPSC-NCCs changes during the inflamed condition. Similar to previous results by GeneChip analysis, mRNA for $T G F-\beta 1$ and $T G F-\beta 2$ in iPSC-NCCs was highly expressed during the inflamed condition, as well as the normal culture condition (Supplementary Fig. S2). These data suggest that NCCs can express and produce these immunosuppressive factors even under inflammatory conditions.

FACS, immunostaining, and qRT-PCR were used to evaluate the expression of TGF- $\beta 2$ and confirm the expression of TGF- $\beta$ on iPSC-NCCs. As shown in Fig. 7A and $\mathrm{B}$, iPSC-NCCs clearly expressed TGF- $\beta 2$ on their surface (=membrane-bound TGF- $\beta 2$ ). In addition, qRT-PCR also showed that iPSC-NCCs significantly expressed mRNA for $T G F-\beta 2$ (Fig. 7C). Based on these findings, we focused on TGF- $\beta$ as a candidate immunoregulatory factor that suppresses $\mathrm{T}$ cells.

FIG. 3. Capacity of iPSC-NCCs to suppress MLR. (A) PBMC mix (healthy donors, $n=5$ ) was cocultured with iPSCNCCs for 5 days. iPSCs and iPSC-RPE cells were also used as controls. After the cultures, PBMCs exposed to iPSC-NCCs were harvested for flow cytometry analysis (Ki-67 FACS). Numbers in the histogram indicate double-positive cells (eg, CD4-Ki-67). These data are representative of three experiments. (B) Percentages of the proliferating cells (double-positive cells of PBMC mix [MLR] and MLR + iPSC-NCCs in Fig. 3A) were also examined. Data are the mean \pm SD of 3 experiments. ${ }^{*} P<0.01$, comparing two groups. MLR, mixed lymphocyte reaction; PBMC, peripheral blood mononuclear cell; RPE, retinal pigment epithelial. 
A PBMCsmix (MLR) MLR + iPSC-NCCs MLR + iPSCs MLR + iPSC-RPE
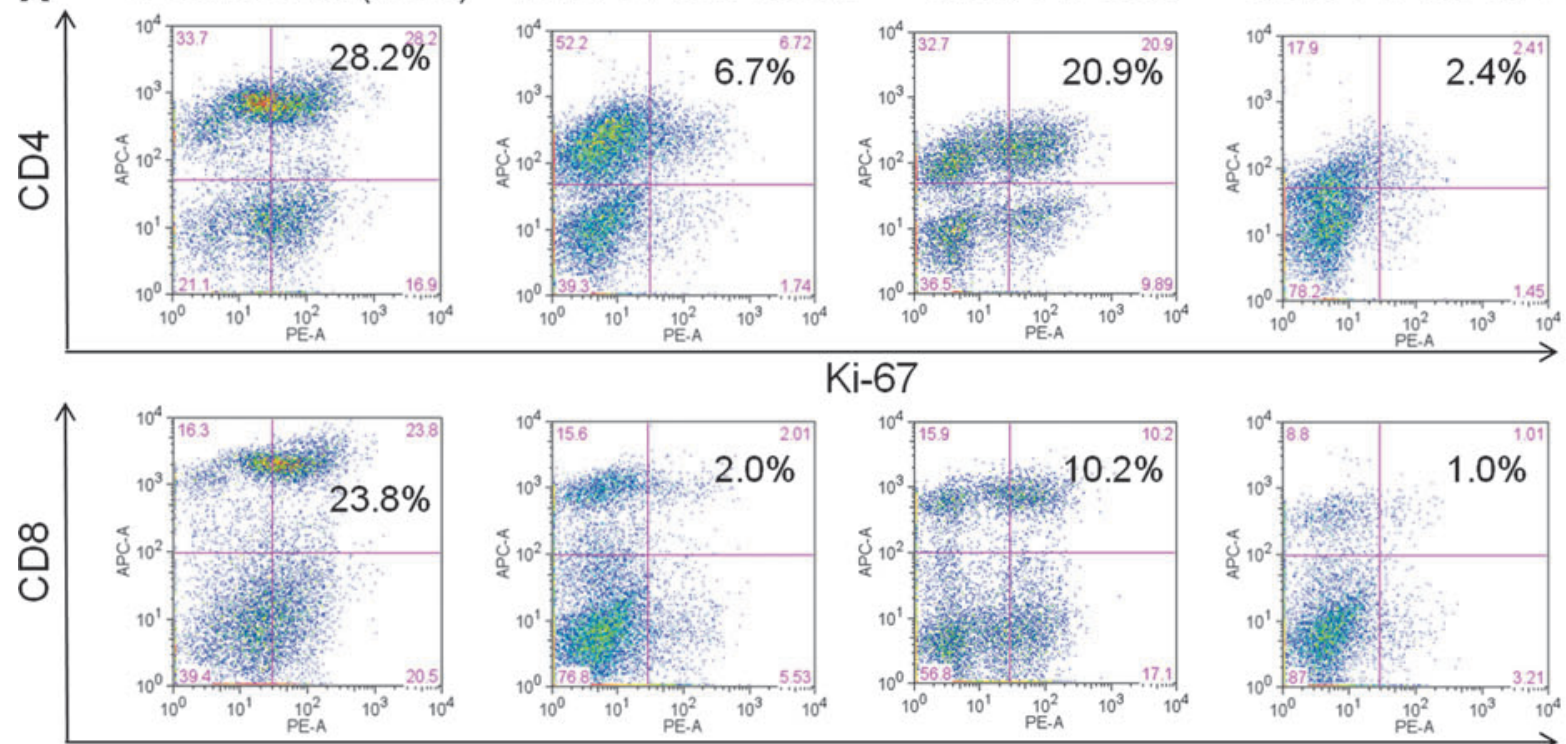

\section{Ki-67}
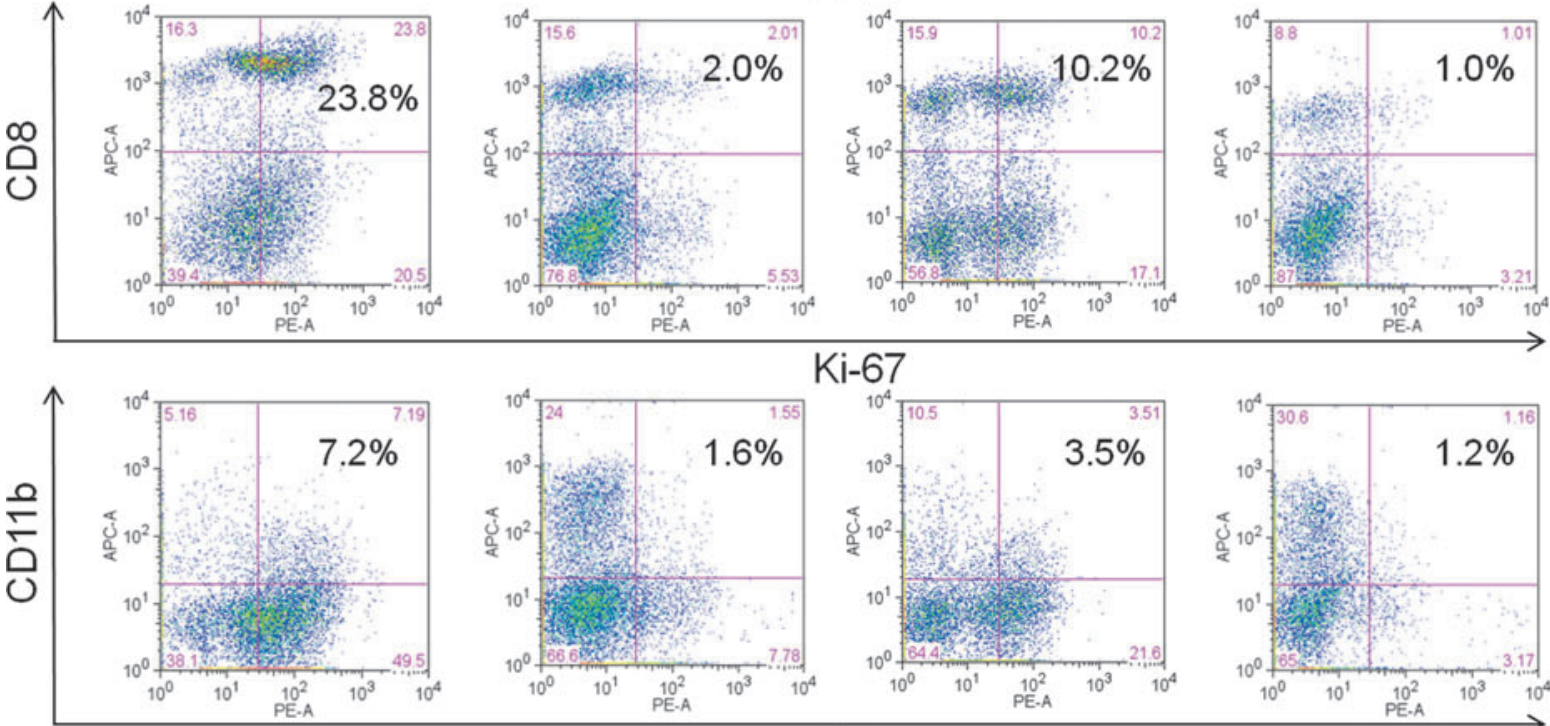

\section{Ki-67}
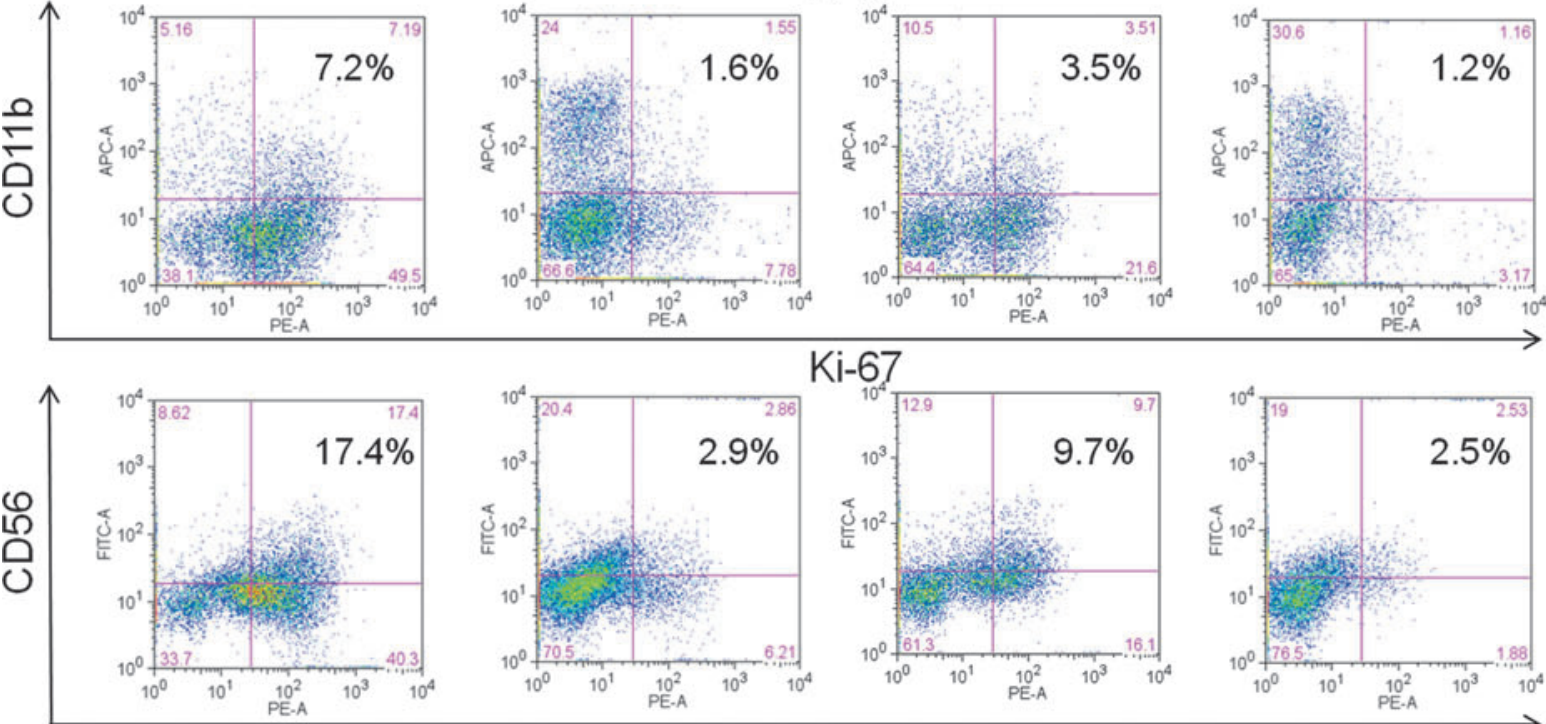

Ki-67
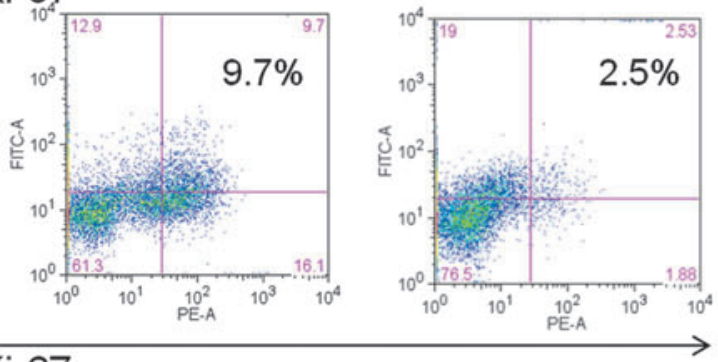

\section{Ki-67}

B

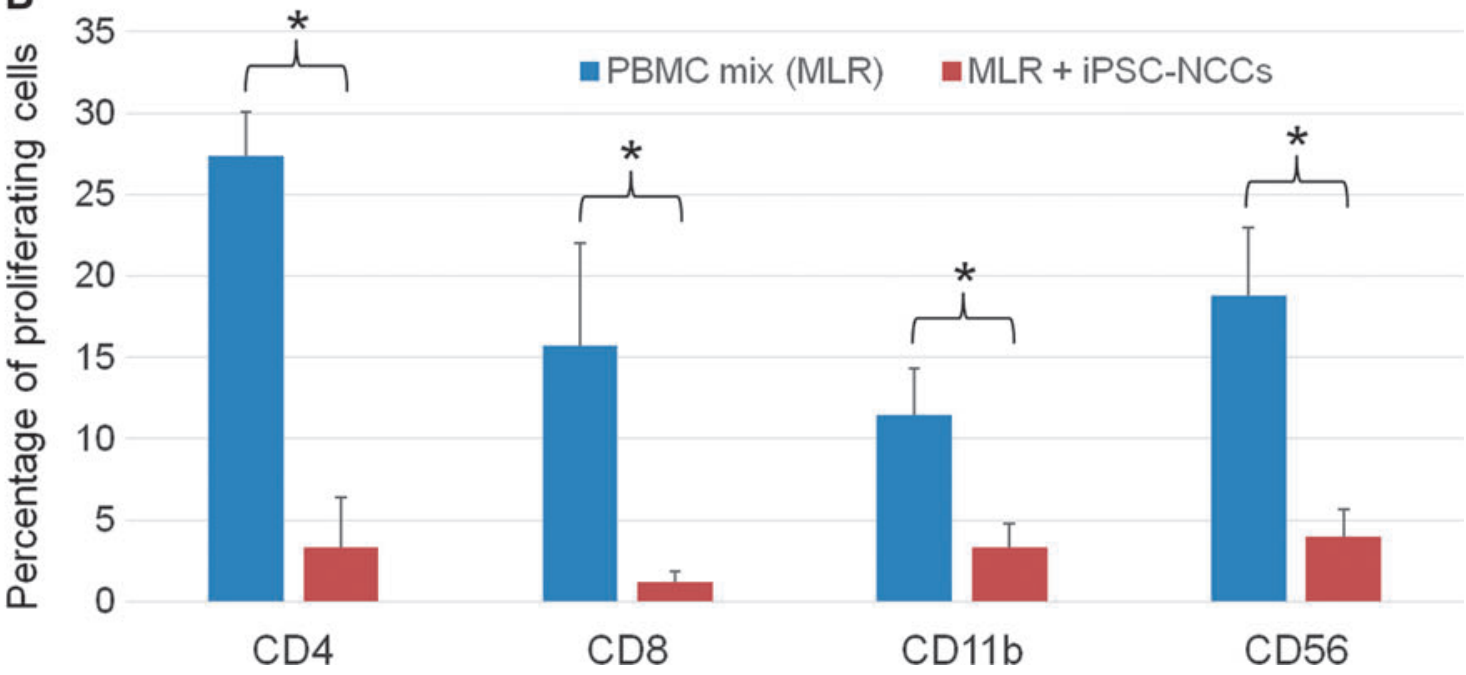


A
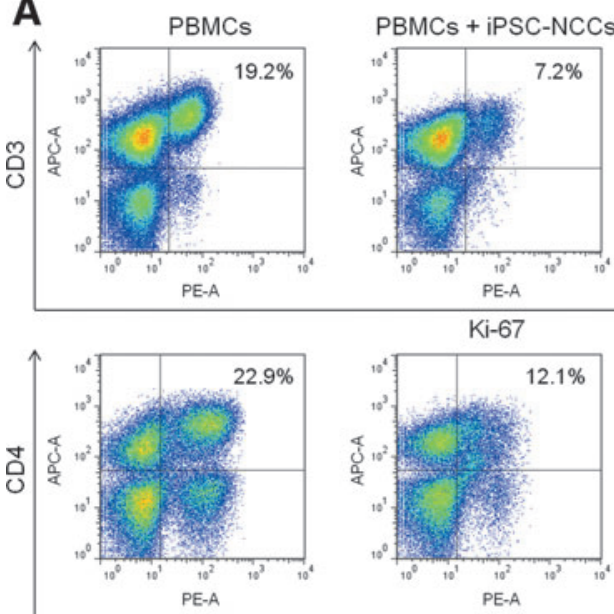

$\frac{\text { PE-A }}{\mathrm{Ki}-67}$

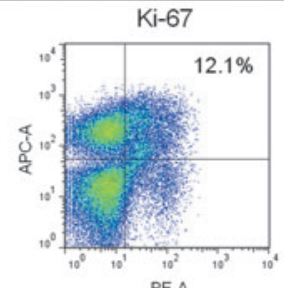

$\mathrm{Ki}-67$
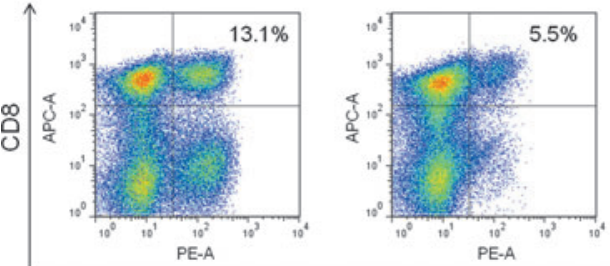

Ki-67

C
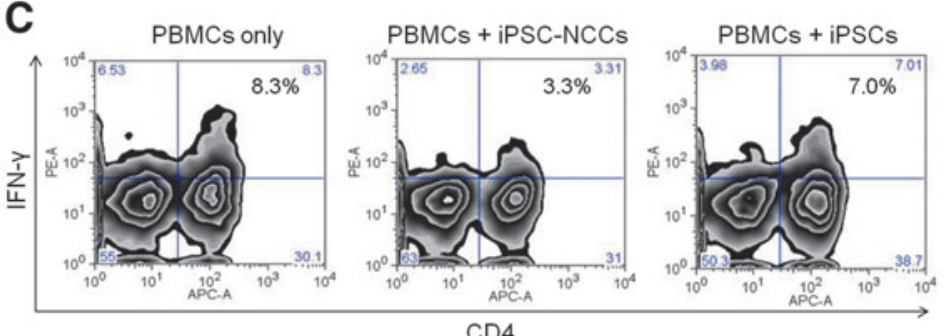

E
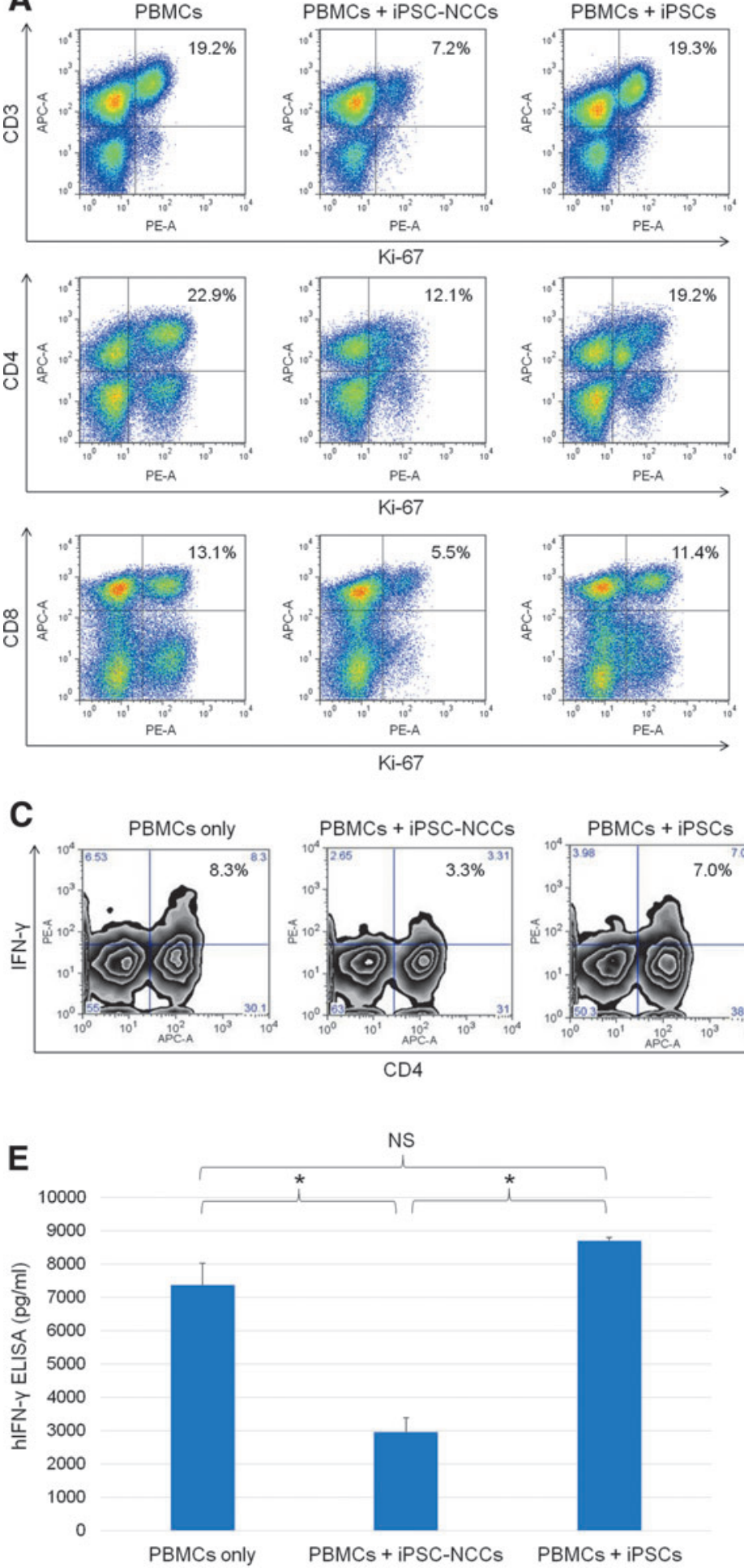

$\rightarrow$
B

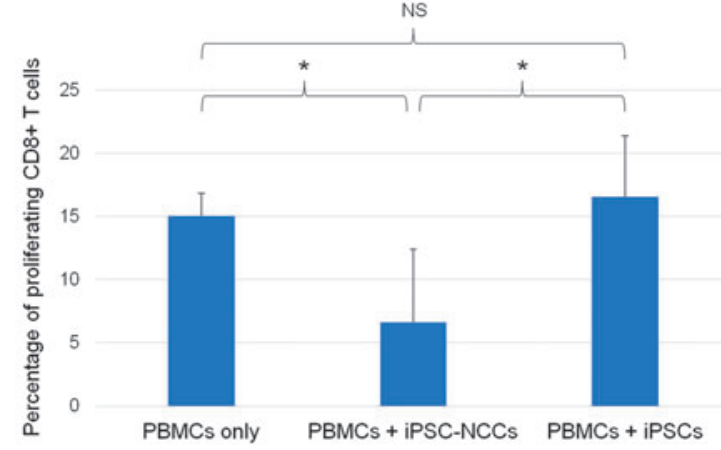

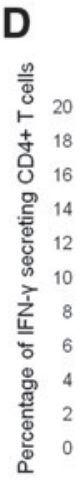
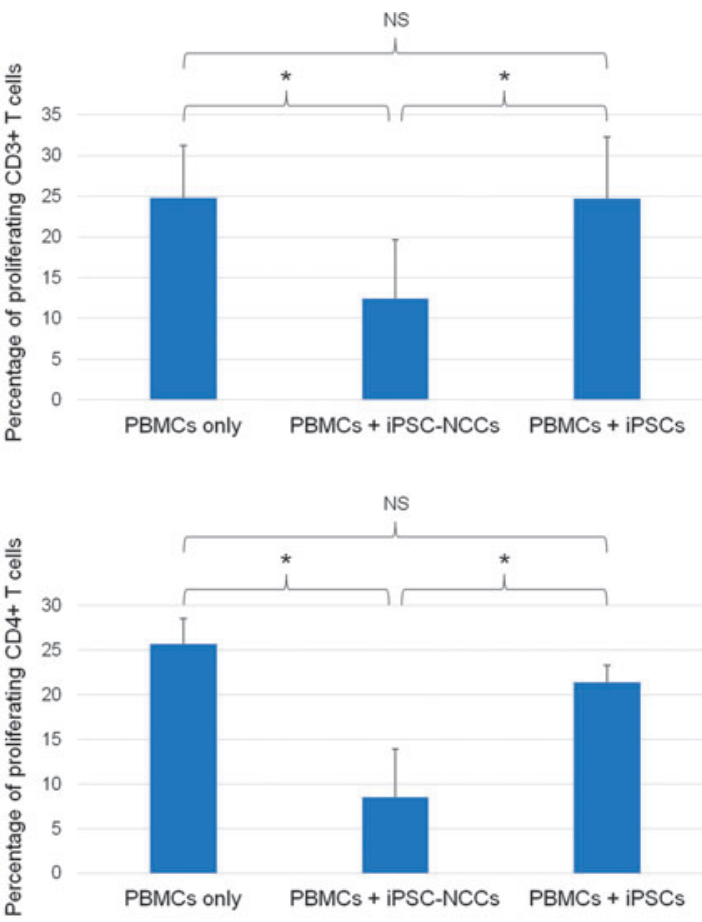

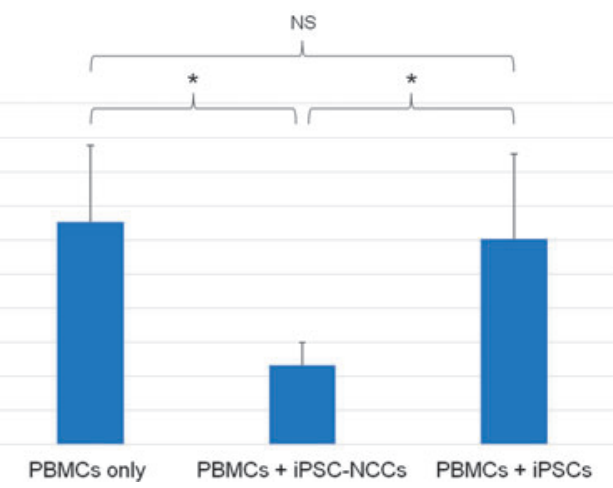

FIG. 4. Capacity of iPSC-NCCs to suppress activation of T cells. (A) PBMCs (a healthy donor) in the presence of anti-CD3 and anti-CD28 antibodies were cocultured with iPSC-NCCs for 3 days. After 3 days, the PBMCs exposed to iPSC-NCCs were harvested for Ki-67 FACS analysis. Numbers in the FACS dot plots indicate double-positive cells (eg, CD3-Ki-67). These data are representative of three experiments. (B) Percentages of the proliferating $\mathrm{T}$ cells (double-positive cells in A) were also examined. Data are the mean \pm SD of three experiments. $* P<0.05$, compared to the two groups. NS, not significant. (C) FACS density plots represent the expression of IFN- $\gamma$ on $\mathrm{CD}^{+} \mathrm{T}$ cells in the presence of iPSC-NCCs or control iPSCs. PBMCs were stained with anti-CD4 and anti-IFN- $\gamma$. Numbers in the density plots indicate the percentage of cells double positive for CD4/IFN- $\gamma$. These data are representative of three experiments. (D) Percentages of the IFN- $\gamma$ secreting CD4 ${ }^{+} \mathrm{T}$ cells (double-positive cells in $\mathbf{C}$ ) were also examined. Data are the mean \pm SD of 3 experiments. $* P<0.05$, compared to the two groups. NS, not significant. (E) Concentrations of IFN- $\gamma$ in supernatant (MLR plus iPSC-NCCs) were examined by human IFN- $\gamma$ ELISA. We also collected control samples: MLR without iPSC-NCCs and MLR plus iPSCs. Data are the mean \pm SD of three ELISA determinations. $* P<0.01$, compared to the two groups. NS, not significant. 
A

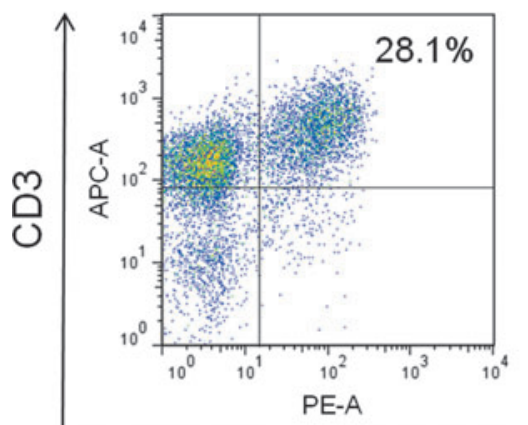

PBMCs + iPSC-NCCs

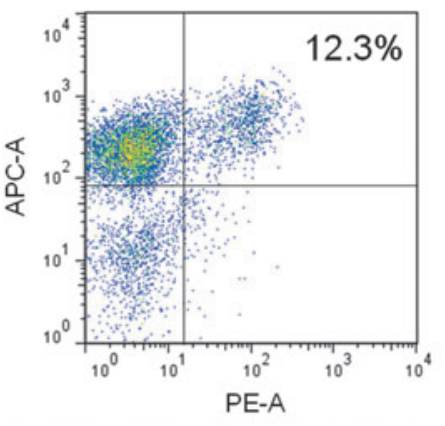

PBMCs + iPSC-NCCs + cell insert

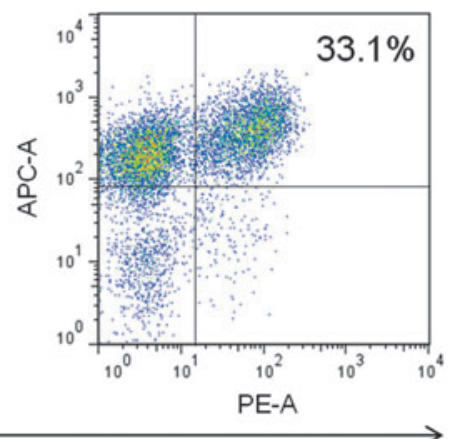

Ki-67

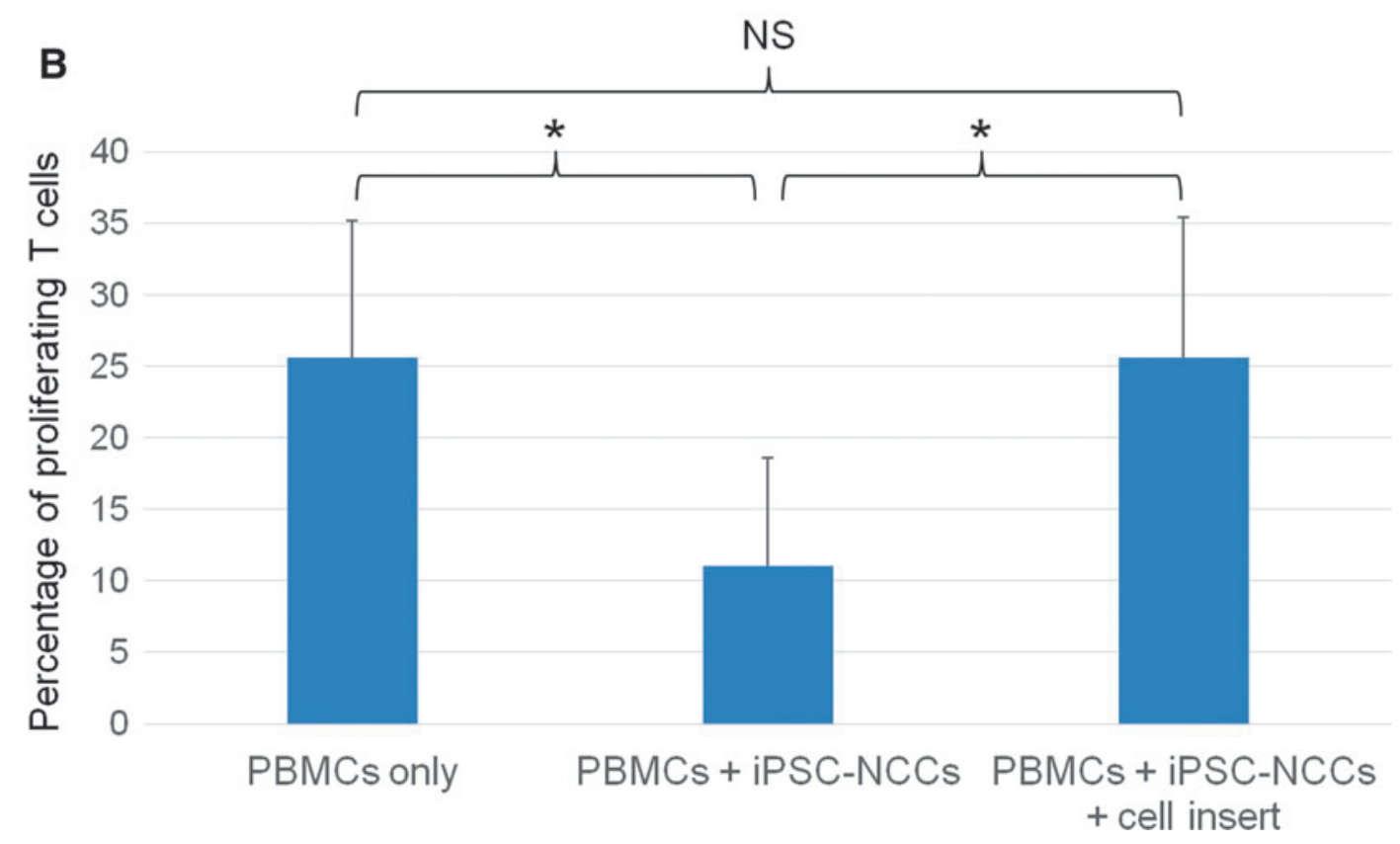

FIG. 5. Ability of iPSC-NCCs to suppress T cells through cell contact molecules. (A) iPSC-NCCs were first cultured in 12-well plates. Transwell cell inserts were placed in these wells, and each transwell contained PBMCs plus anti-CD3 and anti-CD28 antibodies to block cell-to-cell contact between the NCCs and CD3 positive T cells in PBMCs. The numbers in the FACS histograms indicate CD3-Ki-67 double-positive cells. These data are representative of three experiments. (B) Percentages of the proliferating $\mathrm{T}$ cells (double-positive cells in A) were also examined. Data are the mean $\pm \mathrm{SD}$ of three experiments. $* P<0.05$, compared to the two groups. NS, not significant.

\section{Capacity of iPSC-NCCs to suppress T cell activation in the TGF- $\beta$ block assay}

To determine whether TGF- $\beta$ is the major factor responsible for inhibiting $\mathrm{T}$ cell proliferation by iPSC-NCCs, human TGF- $\beta$ RI kinase inhibitor (SB431542) was added to the coculture of PBMCs and iPSC-NCCs. The FACS analysis showed that iPSC-NCCs failed to suppress activated T cells in the presence of $10 \mu \mathrm{M}$ of SB431542 (Fig. 8A). Moreover, there was a statistically significant difference between the PBMC-NCC cocultures and the cultures with $10 \mu \mathrm{M}$ of SB431542 (Fig. 8B). Dose-dependent effects of SB431542 were observed, although there was no statistically significant difference among the doses (Supplementary Fig. S3). SB431542 had no influence on the cell viability of
iPSC-NCCs, and SB431542 itself did not increase the PBMC proliferation (data not shown). In addition, ELISA revealed similar results for IFN- $\gamma$, that is, supernatants from PBMC-NCC cocultures in the presence of SB431542 contained significantly higher levels than that observed for the cocultures without this inhibitor (Fig. 8C). These results demonstrate that the blockers of TGF- $\beta$ RI are able to neutralize the suppression of NCCs. Taken together, our results indicate that TGF- $\beta$ produced by NCCs can be used to suppress bystander $\mathrm{T}$ cells in vitro.

\section{Discussion}

While purification of primary NCCs is possible, obtaining a sufficient quantity for use in experiments can be very 
FIG. 6. Expression of mRNA for HLA-related molecules and immunosuppressive factors in iPSC-NCCs as assessed by DNA microarray. Total RNA of iPSCs $(n=2$, red bars $)$ and iPSC-NCCs $(n=2$, blue bars $)$ was extracted and analyzed by microarray. (A) HLA class I and HLA class II expression. (B) Immunosuppressive molecules. FASLG, Fas ligand; PTGES, prostaglandin $\mathrm{E}$ synthase; $P T G E S 2$, prostaglandin $\mathrm{E}$ synthase 2; PDCD1LG2, programmed death 1 ligand 2; IL10, interleukin 10; NOS1, nitric oxide synthase 1 ; NOS2, nitric oxide synthase $2 ; N O S 3$, nitric oxide synthase 3; IDO1, indoleamine 2,3dioxygenase 1 ; IDO2, indoleamine 2,3-dioxygenase 2 ; TGFB1, transforming growth factor beta 1 ; $T G F B 2$, transforming growth factor beta $2 ; T G F B 3$, transforming growth factor beta 3 .
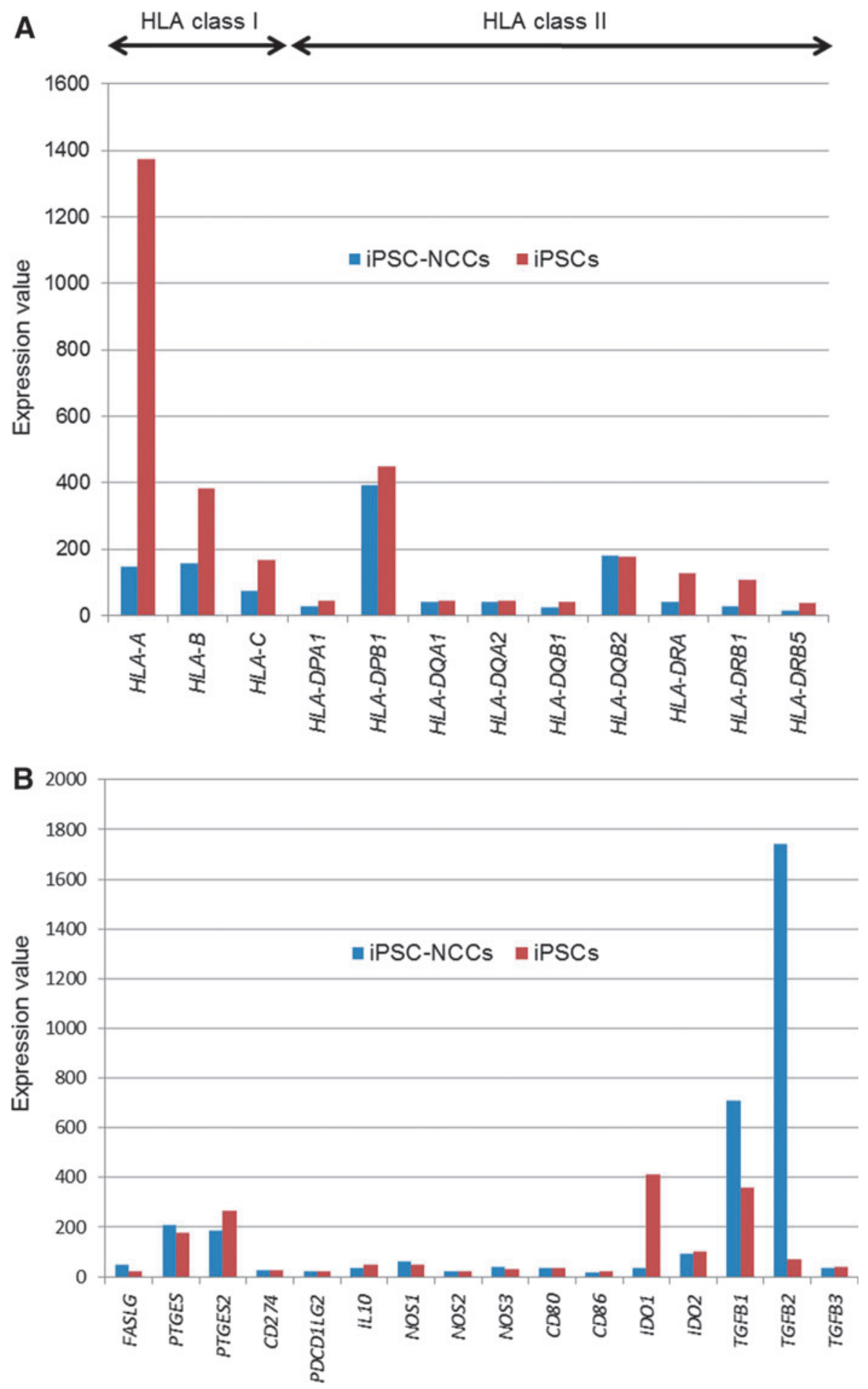

difficult. Although Stemple et al. succeeded in isolating primary NCCs from a rat embryo [33], the amount of NCCs that can be collected from an embryo is limited as the neural crest is an embryonic transient tissue. Moreover, the collection of human primary NCCs is ethically impossible. However, as the protocol used in our current study was able to efficiently produce a large amount of induced NCCs, this made it possible to use NCCs in our present experiments. As we were able to obtain sufficient cell quantities, we were able to successfully examine the immunological properties using human iPSC-NCCs. Moreover, as iPSC-NCCs have poor immunogenicity, this means that they can potentially be used for $\mathrm{T}$ cell suppression. However, to achieve this suppression, TGF- $\beta$ produced by NCCs is an important factor in achieving these immunosuppressive properties.

The neural crest plays an important role in the development of the whole human body. Thus, developmental disorders associated with the neural crest, which are referred to 

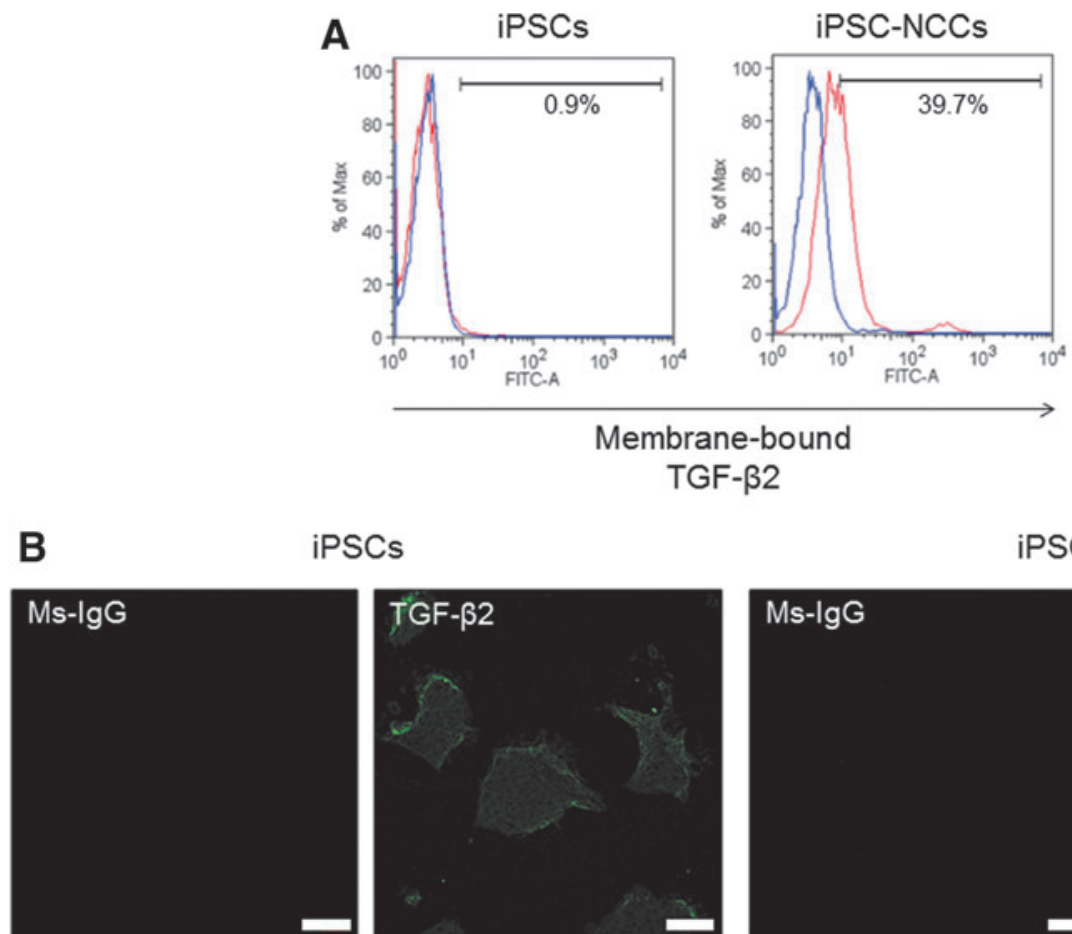

iPSCs

iPSC-NCCs
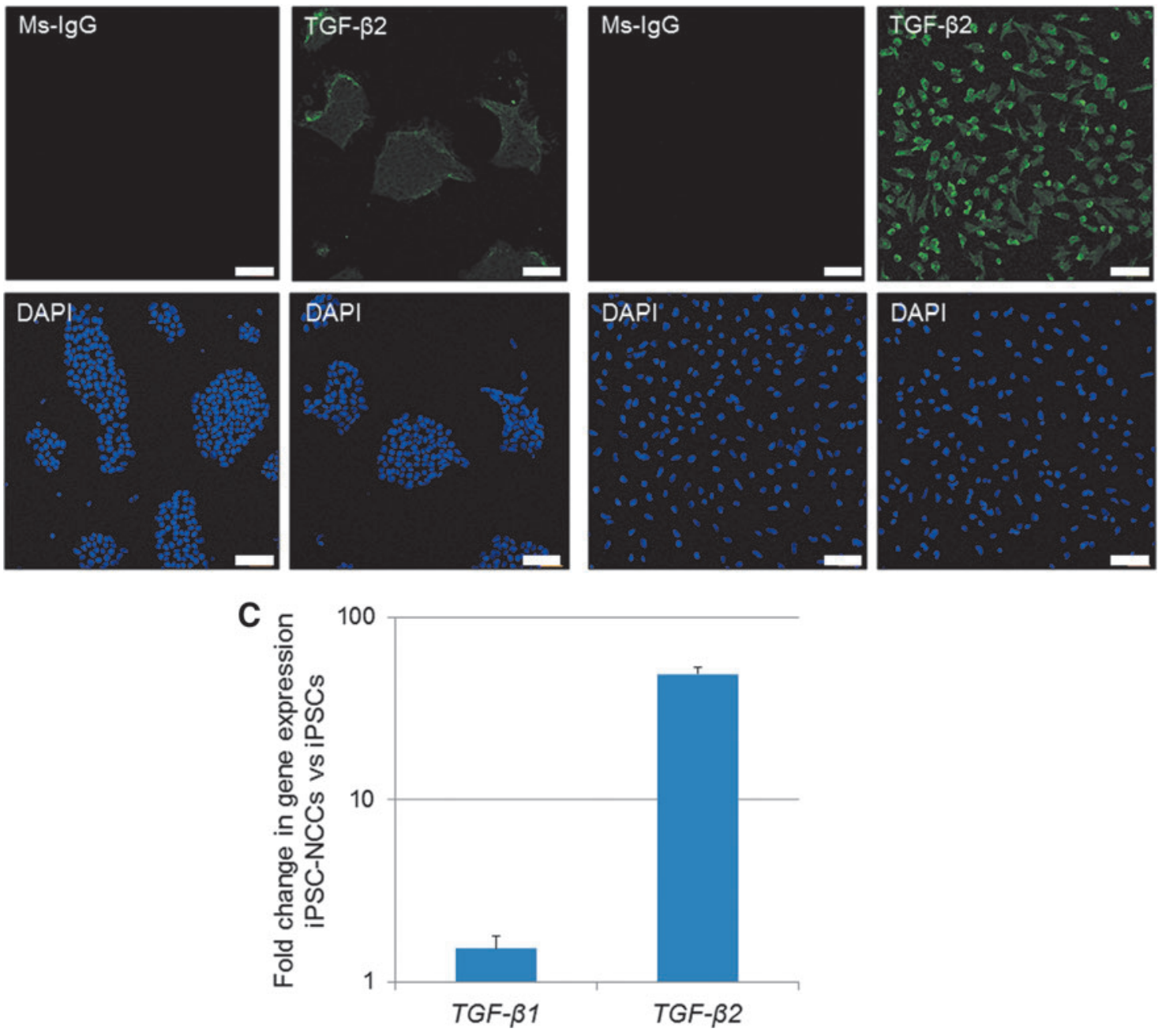

FIG. 7. Expression of membrane-bound TGF- $\beta 2$ on iPSC-derived NCCs. (A) Detection of membrane-bound TGF- $\beta 2$ on iPSC-NCCs by flow cytometry analysis. We also prepared iPSCs as a control. These cells were stained with anti-human TGF- $\beta 2$ abs. Blue histograms represent isotype control staining. (B) Detection of TGF- $\beta 2$ in iPSC-NCCs by immunostaining. iPSC-NCCs, but not control iPSCs, clearly expressed TGF- $\beta 2$ on their surface. Cell nuclei were counterstained with DAPI. Scale bars, $100 \mu \mathrm{m}$. (C) iPSC-NCCs or control iPSCs were harvested and examined for expression of $T G F-\beta 1, \beta 2$ mRNA by qRT-PCR. Results indicate the relative expression of these molecules $(\Delta \Delta \mathrm{Ct}$ : control iPSCs $=1.0)$.

as neurocristopathy, can affect the entire body. Neurocristopathy disorders include Hirschsprung's disease, CHARGE syndrome, and Treacher-Collins syndrome, among others. Eye related complications such as ocular coloboma and heterochromia iridis are often known to arise from such diseases [34]. Furthermore, these complications include not only the above congenital diseases but also degenerative diseases of neural crest-derived tissues such as keratoconus, Fuchs dystrophy, and adult-onset primary open-angle glaucoma [1]. Thus, NCCs induced from neurocristopathy- 

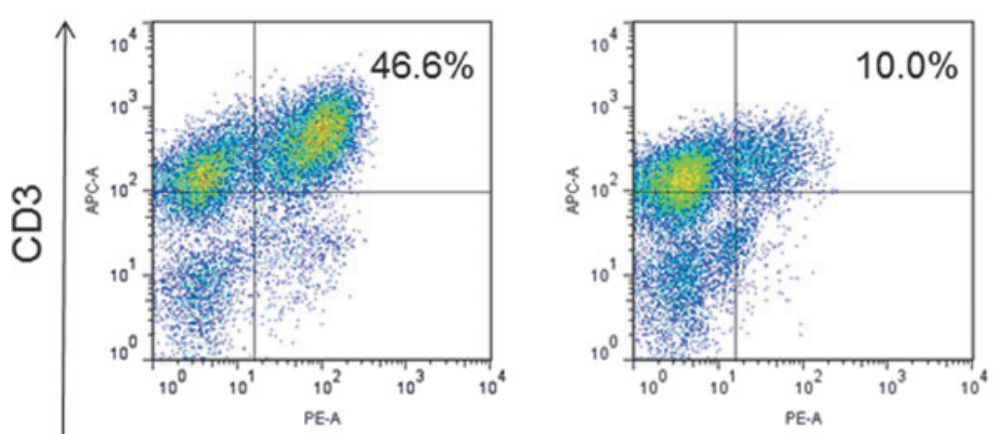
+ SB431542

Ki-67
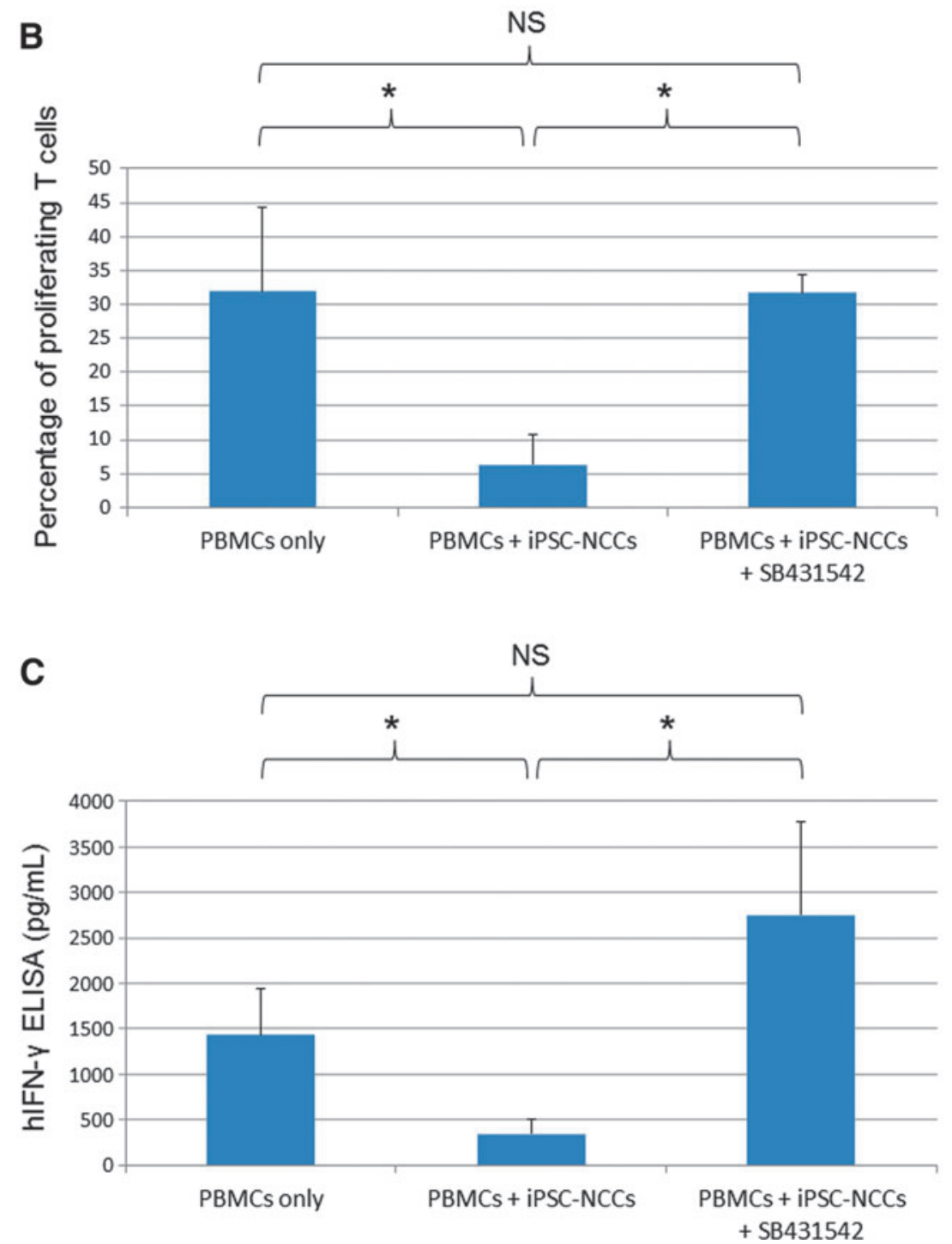

FIG. 8. Effect of TGF- $\beta$ produced by iPSC-NCCs on suppression of T cell activation. (A) PBMCs plus anti-CD3 and antiCD28 antibodies were cocultured with iPSC-NCCs in the presence of $10 \mu \mathrm{M}$ of SB431542 and PBMC-NCCs without SB431542 (middle panel) and evaluated by Ki-67 FACS analysis. Numbers in the histogram indicate double-positive cells. These data are representative of three experiments. (B) Percentages of proliferating T cells (the double-positive cells in A) are examined. Data are the mean \pm SD of three experiments. ${ }^{*} P<0.05$, compared to the two groups. NS, not significant. (C) Concentrations of IFN- $\gamma$ in supernatant are examined by human IFN- $\gamma$ ELISA. We collected samples of PBMCs only and PBMC plus iPSC-NCCs with or without SB431542. Data are the mean \pm SD of three ELISA determinations. $* P<0.05$, comparing two groups. NS, not significant. 
specific iPSCs might be an attractive tool for studying the pathogenesis of neurocristopathies. Okuno et al. reported that iPSC-NCCs from CHARGE syndrome patients exhibited defective migratory activity [35].

In addition, iPSC-NCCs can also be used for various applications. For example, the generation of sufficient iPSCNCC numbers can be used to perform drug screening assays. Moreover, iPSC-NCCs can be utilized as a cell source for improving pathological neurocristopathy conditions. $\mathrm{Li}$ et al. and Schlieve et al. also recently reported that iPSCNCCs differentiated into neurons in human or engineered gut tissues [23,24]. As a result, the transplantation of iPSCNCCs might make it possible to restore the bowel movements of Hirschsprung's disease patients.

The simplicity and high reproducibility of the NCC induction protocols can potentially reveal molecular functions and mechanisms of neural crest originated disorders. If so, this could provide an important insight for novel cell-based medicine. In our current study, we succeeded in inducing NCCs and were able to examine the immunological properties of the iPSC-NCCs. Study results demonstrated that while iPSC-NCCs had a lower expression of HLA class I, they had no expression of HLA class II or positive costimulatory molecules (eg, CD80/CD86) against $\mathrm{T}$ cells, thereby indicating that iPSC-NCCs exhibit poor immunogenicity.

The MLR test in this study demonstrated that iPSCs failed to inhibit PBMC proliferation. Lu et al. previously reported that in contrast to human skin fibroblasts, which significantly induced allogeneic $\mathrm{T}$ cell activation and proliferation, human iPSCs had low or negligible immunogenicity, were able to induce IL-10-secreting regulatory $\mathrm{T}$ cell, and failed to induce $\mathrm{T}$ cell activation and proliferation [36]. In contrast, iPSC-NCCs globally inhibited PBMC proliferation. Since a low level of HLA molecules theoretically increases the susceptibility to attacks by NK cells, this is an important pathway for defending against pathologic microorganisms under normal conditions [37]. The MLR test, however, revealed that iPSC-NCCs did not activate NK cell proliferation. When PBMCs were stimulated with anti-CD3/CD28 agonistic antibodies, iPSC-NCCs inhibited $\mathrm{CD}^{+}$and $\mathrm{CD} 8^{+}$ $\mathrm{T}$ cell proliferation in cocultures. Moreover, iPSC-NCCs inhibited IFN- $\gamma$ expressing $\mathrm{CD}^{+} \mathrm{T}$ cells. Thus, not only do iPSC-NCCs suppress $\mathrm{CD} 4^{+} \mathrm{T}$ cell proliferation but also they inhibit helper T cell function (= suppression of Th1 cells). As per our MLR results (Fig. 3), iPSC-NCCs can also inhibit the IFN- $\gamma$ secretion from potential producers $\left(\mathrm{CD}^{+} \mathrm{T}\right.$ cells, CD $11 \mathrm{~b}^{+}$monocytes/macrophages, and $\mathrm{CD} 56^{+} \mathrm{NK} /$ NKT cells), as well as $\mathrm{CD}^{+} \mathrm{T}$ cells.

Our transwell culture results suggested that cell-to-cell contact was critical in order for iPSC-NCCs to inhibit T cell proliferation. And perhaps more importantly, the iPSCNCCs constitutively expressed membrane-bound TGF- $\beta 2$. In addition, SB431542 (human TGF- $\beta$ RI kinase inhibitor $\mathrm{VI})$ prevented the $\mathrm{T}$ cell suppression mediated by iPSCNCCs. This finding demonstrated that iPSC-NCCs suppressed $\mathrm{T}$ cell activation through membrane-bound TGF- $\beta$. In fact, TGF- $\beta$ is a powerful mediator of inflammatory immune cell suppression [38]. Based on these findings, it has been assumed that iPSC-NCCs are able to suppress T cell activation by delivering membrane-bound TGF- $\beta$ to the migrating T cells that are targeted through the TGF- $\beta$-TGF$\beta$ receptor interactions.
NCCs have immunological properties, which are similar to the corneal endothelial cells, and are derived from the neural crest. Since neural crest derivatives may already have developmentally acquired immunological properties during the neural crest stage, when the differentiation advances from the neural crest, it is then possible that more progressive immunological properties can be gained. Zhao et al. succeeded in inducing corneal endothelial cells from human iPSCs through NCCs [39]. In future studies, we hope to establish iPSC-derived corneal endothelial cells, after which, we will then compare the immunological properties between the NCCs and the corneal endothelial cells.

In conclusion, we successfully induced NCCs from human iPSCs. Using iPSC-NCCs, this makes it possible to determine the molecular functions of NCCs and the pathogenesis of neurocristopathy. iPSC-NCCs are hypoimmunogenic cells that can potentially suppress immune cells, including $\mathrm{T}$ cells. TGF- $\beta$ produced by NCCs plays an important role in $\mathrm{T}$ cell suppression. iPSC-NCCs have been reported to have a potential for wound healing $[21,22]$ and enteric neural transplantation treatment $[23,24]$. The current results may help lead to the development of a new treatment of neurocristopathies. In addition, if iPSC-NCCs are clinically used in humans, it is likely that they will cause less or no inflammation and exhibit optimum wound healing, as they exhibit a low immunogenicity and have the potential for inflammatory immune cell suppression. We believe that the current study findings could contribute to realization of the use of iPSC-NCCs in cell-based medicine.

\section{Acknowledgments}

The authors thank N. Hayashi, K. Iseki, S. Fujino, A. Hono, K. Makabe (Laboratory for Retinal Regeneration, Center for Biosystems Dynamics Research, RIKEN, Kobe), and Department of Pathology, Keio University School of Medicine for their expert technical assistance. This work is supported by the Japan Society for the Promotion of Science (Grant-in-Aid for Scientific Research [KAKENHI] 15K1090) (to S. Hatou) and Keio University Grant-in-Aid for Encouragement of Young Medical Scientists (02-002-0038).

\section{Author Disclosure Statement}

No competing financial interests exist.

\section{References}

1. Williams AL and BL Bohnsack. (2015). Neural crest derivatives in ocular development: discerning the eye of the storm. Birth Defects Res C Embryo Today 105:87-95.

2. Reneker LW, DW Silversides, L Xu and PA Overbeek. (2000). Formation of corneal endothelium is essential for anterior segment development - a transgenic mouse model of anterior segment dysgenesis. Development 127:533542.

3. Xu X, C Chen, K Akiyama, Y Chai, AD Le, Z Wang and $S$ Shi. (2013). Gingivae contain neural-crest- and mesoderm-derived mesenchymal stem cells. J Dent Res 92:825-832.

4. Fournier BP, LS Loison-Robert, FC Ferré, GR Owen, H Larjava and L Häkkinen. (2016). Characterisation of 
human gingival neural crest-derived stem cells in monolayer and neurosphere cultures. Eur Cells Mater 31: 40-58.

5. Davies LC, H Lönnies, M Locke, B Sundberg, K Rosendahl, C Götherström, K Le Blanc and P Stephens. (2012). Oral mucosal progenitor cells are potently immunosuppressive in a dose-independent manner. Stem Cells Dev 21:1478-1487.

6. Takashima Y, T Era, K Nakao, S Kondo, M Kasuga, AG Smith and S Nishikawa. (2007). Neuroepithelial cells supply an initial transient wave of MSC differentiation. Cell 129:1377-1388.

7. Sugita S, Y Usui, S Horie, Y Futagami, Y Yamada, J Ma, T Kezuka, H Hamada, T Usui, M Mochizuki and S Yamagami. (2009). Human corneal endothelial cells expressing programmed death-ligand 1 (PD-L1) suppress PD-1+ T helper 1 cells by a contact-dependent mechanism. Invest Ophthalmol Vis Sci 50:263-272.

8. Yamada Y, S Sugita, S Horie, S Yamagami and M Mochizuki. (2010). Mechanisms of immune suppression for CD8+ $\mathrm{T}$ cells by human corneal endothelial cells via membrane-bound TGFbeta. Invest Ophthalmol Vis Sci 51: 2548-2557.

9. Nauta AJ and WE Fibbe. (2007). Immunomodulatory properties of mesenchymal stromal cells. Blood 110:3499-3506.

10. Aggarwal S and MF Pittenger. (2005). Human mesenchymal stem cells modulate allogeneic immune cell responses. Blood 105:1815-1822.

11. Di Nicola M, C Carlo-Stella, M Magni, M Milanesi, PD Longoni, P Matteucci, S Grisanti and AM Gianni. (2002). Human bone marrow stromal cells suppress T-lymphocyte proliferation induced by cellular or nonspecific mitogenic stimuli. Blood 99:3838-3843.

12. Bartholomew A, C Sturgeon, M Siatskas, K Ferrer, K McIntosh, S Patil, W Hardy, S Devine, D Ucker, et al. (2002). Mesenchymal stem cells suppress lymphocyte proliferation in vitro and prolong skin graft survival in vivo. Exp Hematol 30:42-48.

13. Sato K, K Ozaki, I Oh, A Meguro, K Hatanaka, T Nagai, K Muroi and K Ozawa. (2007). Nitric oxide plays a critical role in suppression of T-cell proliferation by mesenchymal stem cells. Blood 109:228-234.

14. Le Blanc K, I Rasmusson, B Sundberg, C Götherström, M Hassan, M Uzunel and O Ringdén. (2004). Treatment of severe acute graft-versus-host disease with third party haploidentical mesenchymal stem cells. Lancet 363:14391441.

15. Le Blanc K, F Frassoni, L Ball, F Locatelli, H Roelofs, I Lewis, E Lanino, B Sundberg, ME Bernardo, et al. (2008). Mesenchymal stem cells for treatment of steroid-resistant, severe, acute graft-versus-host disease: a phase II study. Lancet 371:1579-1586.

16. Cheng PP, XC Liu, PF Ma, C Gao, JL Li, YY Lin, W Shao, S Han, B Zhao, et al. (2015). iPSC-MSCs combined with low-dose rapamycin induced islet allograft tolerance through suppressing Th1 and enhancing regulatory T-cell differentiation. Stem Cells Dev 24:1793-1804.

17. Menendez L, MJ Kulik, AT Page, SS Park, JD Lauderdale, ML Cunningham and S Dalton. (2013). Directed differentiation of human pluripotent cells to neural crest stem cells. Nat Protoc 8:203-212.

18. Lee G, SM Chambers, MJ Tomishima and L Studer. (2010). Derivation of neural crest cells from human pluripotent stem cells. Nat Protoc 5:688-701.
19. Jaroonwitchawan T, P Muangchan and P Noisa. (2016). Inhibition of FGF signaling accelerates neural crest cell differentiation of human pluripotent stem cells. Biochem Biophys Res Commun 481:176-181.

20. Kreitzer FR, N Salomonis, A Sheehan, M Huang, JS Park, MJ Spindler, P Lizarraga, WA Weiss, PL So and BR Conklin. (2013). A robust method to derive functional neural crest cells from human pluripotent stem cells. Am J Stem Cells 2:119-131.

21. Okawa T, H Kamiya, T Himeno, J Kato, Y Seino, A Fujiya, M Kondo, S Tsunekawa, K Naruse, et al. (2013). Transplantation of neural crest-like cells derived from induced pluripotent stem cells improves diabetic polyneuropathy in mice. Cell Transplant 22:1767-1783.

22. Xu W, Y Wang, E Liu, Y Sun, Z Luo, Z Xu, W Liu, L Zhong, Y Lv, et al. (2013). Human iPSC-derived neural crest stem cells promote tendon repair in a rat patellar tendon window defect model. Tissue Eng A 19:24392451 .

23. Li W, L Huang, J Zeng, W Lin, K Li, J Sun, W Huang, J Chen, G Wang, et al. (2018). Characterization and transplantation of enteric neural crest cells from human induced pluripotent stem cells. Mol Psychiatry 23:499-508.

24. Schlieve CR, KL Fowler, M Thornton, S Huang, I Hajjali, X Hou, B Grubbs, JR Spence and TC Grikscheit. (2017). Neural crest cell implantation restores enteric nervous system function and alters the gastrointestinal transcriptome in human tissue-engineered small intestine. Stem Cell Rep 9:883-896.

25. Bajpai R, DA Chen, A Rada-Iglesias, J Zhang, Y Xiong, J Helms, CP Chang, Y Zhao, T Swigut and J Wysocka. (2010). CHD7 cooperates with PBAF to control multipotent neural crest formation. Nature 463:958-962.

26. Rada-Iglesias A, R Bajpai, S Prescott, SA Brugmann, T Swigut and J Wysocka. (2012). Epigenomic annotation of enhancers predicts transcriptional regulators of human neural crest. Cell Stem Cell 11:633-648.

27. Takahashi K, K Tanabe, M Ohnuki, M Narita, T Ichisaka, K Tomoda and S Yamanaka. (2007). Induction of pluripotent stem cells from adult human fibroblasts by defined factors. Cell 131:861-872.

28. Nakagawa M, M Koyanagi, K Tanabe, K Takahashi, T Ichisaka, T Aoi, K Okita, Y Mochiduki, N Takizawa and S Yamanaka. (2008). Generation of induced pluripotent stem cells without Myc from mouse and human fibroblasts. Nat Biotechnol 26:101-106.

29. Nakagawa M, Y Taniguchi, S Senda, N Takizawa, T Ichisaka, K Asano, A Morizane, D Doi, J Takahashi, et al.. (2014). A novel efficient feeder-free culture system for the derivation of human induced pluripotent stem cells. Sci Rep 4:3594.

30. Sato H, A Idiris, T Miwa and H Kumagai. (2016). Microfabric vessels for embryoid body formation and rapid differentiation of pluripotent stem cells. Sci Rep 6: 31063.

31. Sugita S, H Kamao, Y Iwasaki, S Okamoto, T Hashiguchi, K Iseki, N Hayashi, M Mandai and M Takahashi. (2015). Inhibition of T-cell activation by retinal pigment epithelial cells derived from induced pluripotent stem cells. Invest Ophthalmol Vis Sci 56:1051-1062.

32. Sugita S, Y Iwasaki, K Makabe, T Kimura, T Futagami, S Suegami and M Takahashi. (2016). Lack of T cell response to iPSC-derived retinal pigment epithelial cells from HLA homozygous donors. Stem Cell Rep 7:619-634. 
33. Stemple DL and DJ Anderson. (1992). Isolation of a stem cell for neurons and glia from the mammalian neural crest. Cell 71:973-985.

34. Liu B, DJ Hunter, AA Smith, S Chen and JA Helms. (2014). The capacity of neural crest-derived stem cells for ocular repair. Birth Defects Res C Embryo Today 102:299-308.

35. Okuno H, F Renault Mihara, S Ohta, K Fukuda, K Kurosawa, W Akamatsu, T Sanosaka, J Kohyama, K Hayashi, et al. (2017). CHARGE syndrome modeling using patientiPSCs reveals defective migration of neural crest cells harboring CHD7 mutations. Elife 6:e21114.

36. Lu Q, M Yu, C Shen, X Chen, T Feng, Y Yao, J Li, H Li and W Tu. (2014). Negligible immunogenicity of induced pluripotent stem cells derived from human skin fibroblasts. PLoS One 9:e114949.

37. Yokoyama WM. (2008). Mistaken notions about natural killer cells. Nat Immunol 9:481-485.

38. Rubtsov YP and AY Rudensky. (2007). TGFbeta signalling in control of T-cell-mediated self-reactivity. Nat Rev Immunol 7:443-453.

39. Zhao JJ and NA Afshari. (2016). Generation of human corneal endothelial cells via in vitro ocular lineage restriction of pluripotent stem cells. Invest Ophthalmol Vis Sci 57:6878-6884.
Address correspondence to:

Dr. Sunao Sugita

Laboratory for Retinal Regeneration

RIKEN Center for Biosystems Dynamics Research

2-2-3 Minatojima-minamimachi, Chuo-ku

Kobe 650-0047

Japan

E-mail: sunaoph@cdb.riken.jp

Dr. Shigeto Shimmura Department of Ophthalmology

Keio University School of Medicine 35 Shinano-machi, Shinjuku-ku

Tokyo 160-8582

Japan

E-mail: shige@z8.keio.jp

Received for publication March 16, 2018

Accepted after revision September 21, 2018

Prepublished on Liebert Instant Online September 25, 2018 